\title{
CIHR Canadian HIV Trials Network Coinfection and Concurrent Diseases Core: Canadian guidelines for management and treatment of HIV/hepatitis C coinfection in adults
}

\author{
Mark Hull MD FRCPC 1 , Marina Klein MD FRCPC ${ }^{2}$, Stephen Shafran MD FRCPC ${ }^{3}$, Alice Tseng BScPhm PharmD FCSHP4, \\ Pierre Giguère BPharm MSc${ }^{5}$, Pierre Côté $\mathrm{MD}^{6}$, Marc Poliquin $\mathrm{MD}^{6}$, Curtis Cooper MD FRCPC ; on behalf of The \\ CIHR Canadian HIV Trials Network HIV/Hepatitis C Management and Treatment Guidelines Working Group
}

\begin{abstract}
M Hull, M Klein, S Shafran, et al; on behalf of The CIHR Canadian HIV Trials Network HIV/Hepatitis C Management and Treatment Guidelines Working Group. CIHR Canadian HIV Trials Network Coinfection and Concurrent Diseases Core: Canadian guidelines for management and treatment of HIV/hepatitis C coinfection in adults. Can J Infect Dis Med Microbiol 2013;24(4):217-238.
\end{abstract}

BACKGROUND: Hepatitis C virus (HCV) coinfection occurs in $20 \%$ to $30 \%$ of Canadians living with HIV, and is responsible for a heavy burden of morbidity and mortality. HIV-HCV management is more complex due to the accelerated progression of liver disease, the timing and nature of antiretroviral and HCV therapy, mental health and addictions management, socioeconomic obstacles and drug-drug interactions between new HCV direct-acting antiviral therapies and antiretroviral regimens.

OBJECTIVE: To develop national standards for the management of HCV-HIV coinfected adults in the Canadian context.

METHODS: A panel with specific clinical expertise in HIV-HCV co-infection was convened by The CIHR HIV Trials Network to review

\section{PROCESS STATEMENT}

The concept for the HIV-HCV coinfection guidelines was originated and developed by CC, MK and MH, with CIHR Canadian HIV Trials Network (CTN) and Canadian Association for HIV Research (CAHR) support. All authors contributed to the literature review, writing, editing and final approval (April 2013) of the document. External input was obtained from academic and community-based stakeholder organizations and individuals by a CIHR CTN/CAHR lead online posting of the draft guidelines (March and April 2013) and a CIHR Meeting, Planning and Dissemination Grant-supported HIV-HCV Co-Infection Guidelines Symposium, held April 12, 2013, during the 22nd Annual CAHR Conference (Vancouver, British Columbia).

\section{INTRODUCTION}

Continued improvements in combination antiretroviral therapy (ART) have resulted in sustained gains in projected life expectancy for HIV-infected individuals (1). Long-term management of HIV now increasingly requires assessment and appropriate interventions for comorbid conditions that may impact long-term morbidity and mortality to a greater extent than HIV infection itself. Mortality secondary to chronic hepatitis $\mathrm{C}$ virus (HCV) infection has now surpassed that of HIV in the United States (2) in general, and is a cause of current literature, existing guidelines and protocols. Following broad solicitation for input, consensus recommendations were approved by the working group, and were characterized using a Class (benefit verses harm) and Level (strength of certainty) quality-of-evidence scale.

RESULTS: All HIV-HCV coinfected individuals should be assessed for HCV therapy. Individuals unable to initiate HCV therapy should initiate antiretroviral therapy to slow liver disease progression. Standard of care for genotype 1 is pegylated interferon and weightbased ribavirin dosing plus an HCV protease inhibitor; traditional dual therapy for 24 weeks (for genotype 2/3 with virological clearance at week 4); or 48 weeks (for genotypes 2-6). Therapy deferral for individuals with mild liver disease may be considered. HIV should not be considered a barrier to liver transplantation in coinfected patients. DISCUSSION: Recommendations may not supersede individual clinical judgement.

Key Words: Antivirals; Direct-acting antivirals; HCV; HIV; Pharmacokinetics

significant mortality in coinfected individuals in the ART era (3). Management of HIV-HCV coinfected individuals is more complex relative to HIV monoinfected patients, with issues related to accelerated progression of liver disease, timing and nature of ART and HCV therapy, addictions management and, with the advent of direct-acting antiviral agents (DAAs) for HCV therapy, increasing potential for clinically significant drug-drug interactions with ART regimens. To develop national standards for the management of coinfected individuals, the CIHR Canadian HIV Trials Network convened a panel of physicians and pharmacists with specific expertise in HIV-HCV coinfection, who were tasked with reviewing current literature, existing guidelines and protocols, and adapting them to a Canadian context. The present document reflects the consensus recommendations of this panel and was approved by the committee at large. In an effort to characterize the quality of evidence supporting these recommendations, a Class (reflecting benefit versus harm) and Level (assessing strength of certainty) of evidence scale was used. This system was used for recent Canadian Association for the Study of the Liver guidelines for HCV and HBV management (4,5) (Table 1). These recommendations are intended to aid clinicians in the management of the coinfected patient but may not supersede individual clinical judgement. A summary of these recommendations can be found on page 231 .

${ }^{1}$ University of British Columbia, British Columbia Centre for Excellent in HIV/AIDS, Vancouver, British Columbia; ${ }^{2}$ McGill University, Montréal, Quebec; ${ }^{3}$ University of Alberta, Edmonton, Alberta; ${ }^{4}$ Toronto General Hospital, Toronto; ${ }^{5}$ The Ottawa Hospital Research Institute, Ottawa, Ontario; ${ }^{6}$ Clinique médicale du Quartier Latin, Montréal, Quebec; ${ }^{7}$ University of Ottawa, Ottawa, Ontario

Correspondence and reprints: Dr Curtis Cooper, Department of Infectious Diseases, The Ottawa Hospital General Campus, 501 Smyth Road G12,

Ottawa, Ontario K1H 8L6. Telephone 613-737-8899 ext 72296, e-mail ccooper@ottawahospital.on.ca 


\section{TABLE 1}

\section{Grading system for recommendations}

\begin{tabular}{|c|c|}
\hline Class/Grade & Classification description \\
\hline \multicolumn{2}{|c|}{ Class of evidence } \\
\hline Class 1 & $\begin{array}{l}\text { Conditions for which there is evidence and/or general agreement that a given diagnostic evaluation procedure or treatment is } \\
\text { beneficial, useful and effective }\end{array}$ \\
\hline Class 2 & $\begin{array}{l}\text { Conditions for which there is conflicting evidence and/or a divergence of opinion about the usefulness/efficacy of a diagnostic } \\
\text { evaluation, procedure or treatment }\end{array}$ \\
\hline Class 2a & Weight of evidence/opinion is in favour of usefulness/efficacy \\
\hline Class $2 b$ & Usefulness/efficacy is less well established by evidence/opinion \\
\hline Class 3 & $\begin{array}{l}\text { Conditions for which there is evidence and/or general agreement that a diagnostic evaluation, procedure or treatment is not useful/ } \\
\text { effective and in some cases may be harmful }\end{array}$ \\
\hline \multicolumn{2}{|c|}{ Grade of evidence } \\
\hline Level A & Data derived from multiple randomized clinical trials or meta-analyses \\
\hline Level B & Data derived from a single randomized trial, or nonrandomized studies \\
\hline Level C & Only consensus opinions of experts, case studies or standard of care \\
\hline
\end{tabular}

Adapted from references 5, 211 and 212

TABLE 2

Modelling of HIV-hepatitis C virus (HCV) coinfection according to exposure category

\begin{tabular}{lccc}
\hline & HIV infection, $\mathbf{n}$ & HIV-HCV coinfection, $\mathbf{n}$ (\%) & Proportion in Canada, \% \\
\hline Men who have sex with men & 31,300 & $1316(4.2)$ & 10.0 \\
Men who have sex with men-injection drug users & 2030 & $1665(82.0)$ & 12.7 \\
Injection drug users & 11,180 & $9279(83.0)$ & 70.7 \\
HIV-endemic & 9250 & $139(1.5)$ & 1.1 \\
Heterosexual & 10,710 & $278(2.6)$ & 2.1 \\
Other* & 500 & $450(90.0)$ & 3.4 \\
Total & 65,000 & $13,127(20.2)$ & 100.0 \\
\hline
\end{tabular}

Data from reference 13. *Other exposures include individuals infected by clotting factors and blood transfusions

\section{EPIDEMIOLOGY OF HIV AND HCV COINFECTION}

Epidemiology

In the 30 years since HIV was identified, tremendous progress has been made in its treatment. Once universally fatal, characterized by AIDSrelated opportunistic infections and malignancies, effective combination therapies have rendered HIV infection a manageable chronic condition in developed countries (6). HIV-infected individuals are now surviving for decades after acquiring the infection (7), resulting in comorbidities, such as HCV coinfection, now emerging as significant health problems for HIV-infected individuals. In fact, end-stage liver disease (ESLD) due to HCV is now a primary cause of morbidity and mortality in HIV-infected individuals (8), including in Canada (9).

$\mathrm{HCV}$ infection is recognized as one of the fastest-growing health problems facing industrialized countries, with an estimated 170 million individuals $(10,11)$ and 250,000 Canadians infected $(0.8 \%$ to $1.8 \%$ of the population) (12). In 2008, 13,127 individuals (20\% of the HIV-infected population) were estimated to be coinfected in Canada (Table 2), with significant geographical variations (13). Currently, injection drug use (IDU) is the primary mode of HCV transmission (responsible for approximately $80 \%$ of infections) and is an important risk factor for HIV infection, accounting for an estimated 17\% of new HIV infections in 2008 (14). Although the proportion of new HIV infections attributable to IDU has been in decline over the past decade among men, an increasing trend among women has been observed since 2003. In sentinel sites in Quebec and Ontario, HIV seroprevalence among the injection drug user population peaked at $18.6 \%$ in 2003. From 2003 to June 2008, the prevalence of HCV infection was $63 \%$, and the overall proportion of those coinfected with HIV and HCV was $13 \%$ (15).

Women, youth and Aboriginal injection drug user populations are particularly at risk for coinfection because of shared vulnerabilities. Aboriginal people comprised $3.8 \%$ of the Canadian population in 2006 but $8 \%$ of HIV infections (16). HIV diagnosis among Aboriginal women was 14 times more common than among non-Aboriginal women in 1999 to 2003, and the gap increased to almost 20 times the nonindigenous rate in 2004 to 2008 . High rates of IDU are resulting in parallel increases in HCV coinfection. The highest rates of these new HIV diagnoses are in Saskatchewan, 75\% of which are associated with IDU; consequently, HCV coinfection rates approach 90\% (17). Aboriginal women $<30$ years of age account for a disproportionate number of all new HIV-positive patients in the province. In Vancouver (British Columbia), between 1996 to 2005, the Aboriginal injection drug user population was found to have a significantly elevated baseline prevalence of HIV infection compared with those of other ethnicities (25.1\% versus $16.0 \%)$ (18).

Another important at-risk population are individuals incarcerated in correctional facilities. The elevated prevalence of HIV and HCV infections among inmates has been closely linked to IDU and the sharing of injection equipment. Reports have shown that $30 \%$ to $50 \%$ of Canadian inmates have a history of IDU. For example, in Ontario in 2007, the prevalence of $\mathrm{HCV}$ infection was found to be $15.9 \%$ among men, $30.2 \%$ among women and $54.7 \%$ among injection drug users remanded in provincial facilities. The prevalence of HCV-HIV coinfection was $1.2 \%$ among men and $1.5 \%$ among women. It was highest among older inmates and injection drug users (19). In federal penitentiaries, 31\% of those who had ever been tested for $\mathrm{HCV}$ reported being positive. Aboriginal women reported the highest rate (49\%), more than $50 \%$ higher than the rates among non-Aboriginal women $(30 \%)$ and all men $(30.8 \%)$ (20). The considerable movement between correctional populations both within and outside the correctional system presents numerous opportunities for HIV and HCV transmission.

Acquisition of $\mathrm{HCV}$ is rapid following initiation of IDU and of injecting paraphernalia $(21,22)$. In addition, noninjection smoking paraphernalia has been implicated in HCV transmission (23). Given the risk of HCV morbidity and the high costs of treating HCV among injection drug users (see 'Economic impact'), evidence-based harmreduction strategies should be implemented (23-26). Given the high rate of ongoing drug use during periods of incarceration, often associated with elevated risks of needle sharing, harm-reduction strategies for incarcerated individuals should also be considered (27-29). 
Counselling regarding the risk of acquiring HIV in HCV monoinfected individuals should be undertaken at the time of original diagnosis because subsequent HIV infection may occur if risk behaviours continue (30). All HCV-infected individuals should undergo baseline HIV testing, with repeat testing recommended for those with ongoing risk behaviours for HIV transmission.

\section{Sexual transmission of $\mathrm{HCV}$}

Sexual transmission of $\mathrm{HCV}$ among heterosexuals is rare, estimated to be one in 190,000 episodes of intercourse (31). In contrast, acute HCV infection from sexual transmission has been increasingly observed in HIV-positive men who have sex with men (MSM) (32-34), in whom HCV prevalence now ranges from 4\% to $20 \%$ $(32,35)$. In 2008, in Canada, it was estimated that 1316 MSM were coinfected. In a recent systematic review, HIV-positive MSM had rates of acute $\mathrm{HCV}$ infection that were 3.2 times higher $(0.537$ per 100 person-years) than those of HIV-negative MSM (0.166 per 100 person-years), which is closer to that in the general population and clearly supports routine screening for this population (36). The reasons why MSM may be at increased risk for acquiring HCV has not been fully determined, nor is it clear whether HIV itself enhances either susceptibility or transmission of HCV. Unreported IDU, as well as serosorting, whereby unprotected anal sex occurs only with partners of the same HIV status as their own (37), may be contributory. Factors to be considered in the HIV-positive MSM population include: sexual practices that may lead to transmission through blood contact or concomitant sexually transmitted infections (genital ulcer disease) that may increase susceptibility of transmission rates $(38,39)$; and higher HCV viral loads in the context of HIV and HCV coinfection (38). Transmission networks appear to be quite important in most of the recent reports of acute $\mathrm{HCV}$ among HIV-positive MSM, raising the possibility that certain viral strains play a role (40). The European AIDS Treatment Network (NEAT) Consensus Panel on acute HCV in MSM has previously recommended consideration of screening MSM at risk for acute HCV with testing of liver enzyme levels every six months, and HCV antibody testing annually. For those with ongoing IDU or recent sexually transmitted infection, screening every three months was recommended by the NEAT panel (41). A recent cost-effectiveness analysis of screening options to detect acute HCV among MSM concluded that the strategy of liver enzyme testing every six months in combination with annual HCV screening was cost effective in communities with incidence $<1.25$ per 100 person-years, while screening using liver enzyme levels every three months was optimal in communities with higher incidence (42).

\section{RECOMMENDATION}

1. All HIV-positive individuals should undergo screening for HCV antibodies when first evaluated. Screening should be repeated periodically - at least annually, particularly for high-risk individuals initially found to be negative (such as active injection drug users, Aboriginal peoples and individuals who are/have been incarcerated). HIV-positive MSM should undergo screening for $\mathrm{HCV}$ antibodies annually in combination with testing of liver enzyme levels every six months if sexually active with high-risk behaviours, and repeat $\mathrm{HCV}$ antibody testing (with consideration of additional HCV RNA testing) should be performed whenever unexplained elevations in liver enzyme levels are noted (Class 2a, Level C).

2. Identification of HCV coinfection in HIV provides opportunities for prevention of transmission, risk reduction, counselling, and linkage to care and harm-reduction services (Class 1, Level C).

Coinfected individuals are highly vulnerable in a number of ways that impact health, access to care and treatment. This can be illustrated with data from the Canadian Coinfection Cohort (CCC) study (CTN222), a CIHR-funded prospective cohort that follows 1010 individuals with HIV-HCV coinfection (www.cocostudy.ca) (43). Participants experience very high rates of social instability and poverty. Aboriginal peoples are disproportionately represented in the cohort: $15 \%$ of the cohort overall and 33\% in British Columbia self-identified as Aboriginal; a very high proportion of these were women (62\%). Overall, 458 (57\%) had been previously incarcerated (78\% of Aboriginal peoples versus $53 \%$ of non-Aboriginal peoples) and $44 \%$ reported a psychiatric diagnosis. There are very high rates of past and current (past six months) substance use among participants, with $81 \%$ reporting a history of IDU (38\% were currently injecting; $23 \%$ sharing needles); $50 \%$ were current alcohol drinkers (31\% reported binge/hazardous drinking, defined as $>6$ drinks/day) and $77 \%$ currently smoked cigarettes (43).

\section{Distribution of HCV genotypes in Canada}

The most important predictor of treatment response has been $\mathrm{HCV}$ genotype, with more favourable responses to standard pegylated interferon and ribavirin apparent among genotypes 2 and 3, and lower response rates among genotypes 1 and 4 . In Canada, $62 \%$ of HCV infections are genotype 1 . Among injection drug users, genotypes 1 and 3 are most common. Genotypes $2 \mathrm{a}$ and 5 are more frequent among patients previously exposed to multiple injections, surgery or transfusions, and genotype 4 is more frequent among African immigrants. The existence of several genotypes in Canada despite the low prevalence of HCV reflects the diversity of the population and active immigration (44). Several recent global outbreaks of HCV among HIV-positive MSM have been attributed to genotype 4 infections (45).

\section{The effect of HIV on the natural history of HCV}

In HCV monoinfection without concurrent excess alcohol consumption, it generally takes a minimum of 20 to 30 years for HCV to cause significant liver disease such as cirrhosis, decompensated cirrhosis and/or liver cancer (46). HIV infection exerts a negative impact on this time course. Coinfected individuals progress more rapidly to liver fibrosis, cirrhosis and ESLD compared with those infected with HCV alone (47-50). In a meta-analysis, the RR for cirrhosis was 2.49 (95\% CI 1.81 to 3.42 ) in ART-untreated and 1.72 (95\% CI 1.06 to 2.80) in ARTtreated coinfected versus monoinfected individuals (50). Once cirrhosis develops, there is also a dramatic sixfold acceleration to decompensation and death (47). Fibrosis rates in HIV-infected MSM acquiring acute $\mathrm{HCV}$ while on ART have also been shown to be surprisingly rapid, suggesting an accelerated course of HCV despite effective HIV control (51). This more rapid course is driving, in large measure, the increased liver-related mortality that has been observed worldwide in developed countries in the post-ART era. In a large HIV cohort collaboration (the Data Collection on Adverse events of Anti-HIV Drugs [D:A:D] study), liver-related deaths (14\% overall) were second only to AIDS and were associated with coinfection (3). The proportion of deaths from ESLD among HIV-infected individuals in France increased from 1.5\% in 1995 to $17 \%$ in 2005 (52); $80 \%$ of these were attributable, in part, to $\mathrm{HCV}$ coinfection (53). In the CCC, very high progression rates of fibrosis and the occurrence of clinical ESLD events have been observed - rates approximately six times higher than those reported in HCV monoinfected populations with similar duration of infection. Indeed, ESLD has emerged as the primary cause of death among cohort participants. While alarming, these data may actually be an underestimation of the true burden of disease in this population given that this cohort only includes patients seeking and following regular care.

Coinfected individuals are at risk for the development of hepatocellular carcinoma (HCC). Population-based assessments have demonstrated increased incidence among coinfected patients in some studies ( 1.32 per 1000 person-years compared with 0.20 per 1000 personyears in HIV monoinfected patients) (54) but not others (55), and incidence may be increasing over time (56). Development of HCC occurs at a younger age in coinfected patients, and may be associated with degree of immune suppression in some studies $(57,58)$.

\section{Health economic impact}

Among infectious diseases, $\mathrm{HCV}$ is associated with the largest burden of disease, both because of the frequency of the infection and its consequences (59). HCV infection has become the primary indication for liver 
TABLE 3

Current recommendations in international guidelines for HIV treatment initiation in hepatitis C virus (HCV) coinfected individuals

\begin{tabular}{|c|c|c|}
\hline Guidelines, year (reference) & HCV coinfection & Class/Grade of evidence \\
\hline IAS-USA Guidelines, 2012 (66) & ART regardless of CD4 cell count & Blla \\
\hline US DHHS Guidelines, 2012 (67) & ART regardless of CD4 cell count & BII \\
\hline British HIV Association Guidelines, 2012 (68) & ART if CD4 count $<500$ cells $/ \mu \mathrm{L}$ & IC \\
\hline
\end{tabular}

European AIDS Clinical Society Guidelines, 2012 (69) ART if CD4 count $<500$ cells/ $\mu \mathrm{L}$;

$\geq 500$ cells/ $\mu \mathrm{L}$ : consider ART if HCV therapy not feasible

ART Antiretroviral therapy; IAS-USA International Antiviral Society - United States; US DHHA United States Department of Health and Human Services

transplantation in the developed world. It has been estimated that the costs of treating the chronic sequelae of $\mathrm{HCV}$ among injection drug users in Canada will rise to $\$ 210$ million annually by 2026 (60). Strategies to reduce $\mathrm{HCV}$ transmission in high-risk groups such as injection drug users should, therefore, be considered (Section I).

\section{MANAGING HIV IN THE SETTING OF COINFECTION}

The management of HIV infection in the context of coinfection requires consideration of several factors:

- Effect of ART on the natural history of liver disease;

- Timing of initiation of ART;

- Risk of hepatotoxicity when ART is initiated;

- Potential for drug-drug interactions when undertaking HCV therapy;

- Adherence to ART and HCV therapy, particularly among those with active addiction concerns; and

- Selection of regimens with decreased risk for similar adverse events to those associated with HCV therapy.

\section{Effects of ART on HCV natural history and timing of} ART initiation

Coinfected individuals experience faster progression of HCV disease, with higher risk of ESLD, particularly when both HIV and HCV remain untreated $(47,49)$. In an analysis of coinfected individuals in the preART era, the mean time from infection to cirrhosis was as short as 6.9 years compared with 23.2 years in monoinfected patients (49). Subsequent data have suggested that initiation of ART may serve to slow the rate of fibrosis progression and, hence, delay the onset of ESLD. Brau et al (61) conducted a retrospective analysis of $656 \mathrm{HCV}$ patients ( 274 coinfected with HIV) and determined a fibrosis progression rate as biopsy-determined fibrosis score/duration of HCV infection. Fibrosis progression rates were highest in HIV-infected individuals with detectable HIV plasma viral load but were similarly reduced in HIV-infected individuals with suppressed viral load and in HCV monoinfected patients. Other analyses have shown similar protective effects of longer duration of ART therapy and reduced biopsy-proven fibrosis (62).

Initiation of ART has also been shown to reduce liver-related mortality in coinfected patients. In a cohort of 285 coinfected patients initiating either limited ART $(n=55)$ or full ART $(n=93)$, or remaining untreated between 1990 and 2002, liver-related mortality rates were lowest in those receiving ART ( 0.45 per 100 person-years) or dual therapy ( 0.69 per 100 person-years), and highest in those who received no therapy (1.70 per 100 person-years) (63). In a cohort of 472 HIV-infected patients (256 of whom were coinfected with HCV), $41 \%$ of overall mortality was due to liver-related deaths and, in Cox regression analysis, receipt of zero to two antiretroviral agents compared with ART was associated with an RR of 2.9 (95\% CI 1.3 to 6.7) for liver-related mortality (64). Overall evidence derived from these and other cohort studies supports ART-related decreases in fibrosis progression and potential reduction in liver-related mortality (65).

These data have been incorporated into current treatment guidelines for HIV-infected individuals, in which underlying HCV coinfection is recognized to be a potential reason to consider early initiation of ART at relatively high CD4 cell counts (Table 3) (66-69). The
International Antiviral Society-USA and US Department of Health and Human Services guidelines recommend initiation of ART regardless of CD4 cell count, whereas the British and European guidelines recommend initiation of ART in individuals with CD4 cell count $<500$ cells $/ \mu \mathrm{L}$ (compared with $<350$ cells/ $\mu \mathrm{L}$ for a general treatment initiation threshold) $(68,69)$.

In all circumstances with CD 4 cell counts $\geq 500$ cells/ $\mu \mathrm{L}$, it may be ideal to consider initiating HCV therapy first to avoid potential drugdrug interactions (see below), decrease risk of ART-related hepatotoxicity (70) and, potentially, improve HCV therapy outcome with high baseline CD4 cell count. If HCV therapy is not considered to be imminent or feasible due to competing comorbid conditions, ART initiation at CD4 counts $\geq 500$ cells $/ \mu \mathrm{L}$ should be considered.

\section{RECOMMENDATIONS}

3. Initiation of ART may serve to slow progression of liver disease in coinfected patients. Early initiation of ART is recommended for all individuals with CD4 cell count $<500$ cells/ $\mu$ L (Class 1 , Level B).

4. Initiation of ART in individuals with CD4 cell count $\geq 500$ cells $/ \mu \mathrm{L}$ can be considered if initiation of HCV therapy is not believed to be an option (Class 2a, Level B) in patients who have undergone thorough assessment of barriers to ART adherence and counselling regarding the long-term nature of ART.

\section{ART and accelerated hepatic fibrosis}

A direct causative association between ART and fibrosis progression in coinfected patients has not been well established and may be subject to additional confounders when assessed in terms of underlying alcohol or substance use, differing classes of antiretroviral agents and the potential beneficial effects on hepatic disease progression associated with initiation of ART, as described above. Nevertheless, a potential association between ART and fibrosis progression has been observed in some studies $(71,72)$. Further evaluation of this potential interaction is required.

\section{ART and risk of hepatotoxicity in coinfected individuals}

Hepatotoxicity is usually defined using the AIDS Clinical Trial Group grading system, with grade 3 (alanine aminotransferase [ALT] elevations $>5 \times$ the upper limit of normal [ULN] range in individuals with normal values at baseline) considered to be a standard for more severe disease. Some experts have proposed an additional classification, with grade 3 elevation considered to be $>3.5 \times$ ULN when baseline values are abnormal (73). Overall, the incidence of hepatotoxicity in observational studies ranges from $2 \%$ to $18 \%(74)$, and the presence of HCV coinfection increases the risk by at least two- to five-fold $(75-78)$. Studies performed in the early ART era revealed increased risk of hepatotoxicity among coinfected individuals initiating ART containing the early protease inhibitors (PIs), particularly high-dose ritonavir $(73,78,79)$, although other antiretrovirals with known hepatotoxicity profiles, such as the non-nucleoside reverse-transcriptase inhibitor (NNRTI) nevirapine, have also been implicated (80).

Tolerability of current first- and second-line NNRTI and PI agents in coinfected patients has been assessed in post hoc analysis of phase II and III randomized clinical trials, including newer agents such as raltegravir (81), rilpivirine (82), etravirine (83) and darunavir (84), 
although relatively small numbers of coinfected individuals were included in the latter. Presently, there is limited information regarding use of the new boosted integrase inhibitor elvitegravir/cobicistat in coinfected patients, because HCV coinfection was identified in 5\% of individuals randomly assigned to this combination in trials comparing it with both efavirenz or atazanavir/ritonavir $(85,86)$. Nonetheless, no significant hepatotoxicity was noted.

Risk of antiretroviral-related hepatotoxicity has been associated with degree of underlying liver fibrosis. In a prospective study involving 107 patients with biopsy-confirmed fibrosis ranging from F0 to F4, the overall incidence of hepatotoxicity was 5.1 events per 100 personyears. However, the incidence among those with F3/4 fibrosis was 38\% compared with $15 \%$ among those with F1/2 fibrosis (RR 2.75 [95\% CI 1.08 to 6.97]) (87). In some studies, infection with HCV genotype 3 has also been associated with increased risk for hepatotoxicity $(88,89)$.

Successful HCV therapy has been associated with potential decrease in risk for subsequent antiretroviral-related hepatotoxicity (70). In a cohort of 132 coinfected patients, sustained virological response (SVR) following HCV therapy was achieved in $33 \%$ of individuals. The yearly incidence rate of antiretroviral hepatotoxicity among those with SVR was $3.1 \%$ versus $12.9 \%$ among those without SVR (70).

Presently, no specific antiretroviral regimen can be preferentially recommended for use in coinfected patients. However, certain regimens may need to be used cautiously in the setting of advanced liver disease. Close monitoring is required, and dosage adjustments or alterations of combination ART may be required if hepatic decompensation occurs (67). Certain antiretroviral agents must be avoided altogether due to drug-drug interactions when HCV therapy containing HCV PIs is being initiated (see 'Drug-drug interaction' section).

\section{RECOMMENDATIONS}

5. Current first- and second-line ART regimens should be initiated as per current guidelines because they are effective and welltolerated in coinfected patients (Class 1, Level A).

6. HCV therapy should be considered before ART initiation in individuals with early HIV disease as a potential means of decreasing risk of antiretroviral-related hepatotoxicity and to avoid risk of drug interactions between ART and HCV therapies (Class 2a, Level C).

\section{BASELINE EVALUATION AND MANAGEMENT OF HCV IN COINFECTED PATIENTS}

Baseline evaluation and monitoring of coinfected patients is similar to that of monoinfected patients and should focus on determination of degree of liver disease/hepatic fibrosis as a prelude to consideration of HCV therapy (Table 4). Additional monitoring is required for patients with underlying cirrhosis, and steps to prevent additional viral hepatitis infections should be considered.

\section{Diagnosis}

In Canada, as many as $25 \%$ to $30 \%$ of HIV-HCV coinfected individuals are estimated to be unaware of their infection. Thus, there is a clear need to increase testing. Identification of HIV-HCV coinfection provides opportunities for prevention of transmission, risk reduction, counselling, and linkage to care and harm-reduction services.

All HIV-infected patients should be screened for HCV coinfection using serological testing. In individuals with significant immune compromise, the HCV antibody may occasionally be falsely negative, and consideration should be given to directly testing for the presence of HCV RNA (90).

The frequency of testing for HCV infection should depend on ongoing risk behaviours (Section I). Detection of HCV antibody does not determine active infection. The presence of HCV RNA should be confirmed to rule out spontaneous clearance using qualitative or quantitative polymerase chain reaction. In the EuroSIDA cohort, $23 \%$ of anti-HCV-positive individuals tested HCV RNA negative (91).
TABLE 4

Baseline assessment of coinfected patients

\begin{tabular}{|c|c|c|}
\hline & Test & Comment \\
\hline \multicolumn{3}{|c|}{ Viral hepatitis HCV antibody } \\
\hline \multirow[t]{6}{*}{ screens } & Quantitative HCV RNA & \\
\hline & HCV genotype & \\
\hline & Hepatitis B surface antigen & Chronic HBV infection \\
\hline & Hepatitis B surface antibody & Immunity to HBV \\
\hline & Hepatitis B core antibody & \\
\hline & Hepatitis A immunoglobulin G & $\begin{array}{l}\text { Indicates need for HAV } \\
\text { vaccine }\end{array}$ \\
\hline \multirow[t]{4}{*}{ Liver-related } & Complete blood count & $\begin{array}{l}\text { Thrombocytopenia may } \\
\text { indicate advanced liver } \\
\text { disease }\end{array}$ \\
\hline & $\begin{array}{l}\text { Alanine aminotransferase; } \\
\text { aspartate aminotransferase; } \\
\text { alkaline phosphatase; gamma- } \\
\text { glutamyltransferase }\end{array}$ & \\
\hline & $\begin{array}{l}\text { Albumin, international } \\
\text { normalized ratio, } \\
\text { total bilirubin }\end{array}$ & $\begin{array}{l}\text { Abnormalities suggest } \\
\text { advanced liver disease }\end{array}$ \\
\hline & Ultrasound & \\
\hline \multirow{6}{*}{$\begin{array}{l}\text { Screens for } \\
\text { other } \\
\text { chronic } \\
\text { conditions } \\
\text { of liver } \\
\text { disease }\end{array}$} & Alpha-1-antitrypsin & Alpha-1-antitrypsin deficiency \\
\hline & $\begin{array}{l}\text { Antinuclear antibody, anti- } \\
\text { smooth muscle antibody }\end{array}$ & Autoimmune hepatitis \\
\hline & Antimitochondrial antibody & Primary biliary cirrhosis \\
\hline & Ceruloplasmin & Wilson disease \\
\hline & Ferritin, iron studies & Hemochromatosis \\
\hline & Immunoglobulins A, G and M & $\begin{array}{l}\text { Autoimmune hepatitis, } \\
\text { primary biliary cirrhosis, } \\
\text { alcoholic liver disease }\end{array}$ \\
\hline
\end{tabular}

HAV Hepatitis A virus; HBV Hepatitis B virus; HCV Hepatitis C virus

Individuals with positive HCV RNA tests should undergo determination of HCV genotype as an initial step of determining the nature of subsequent HCV therapy (Section IV).

Individuals with baseline negative HCV RNA should be considered for repeat testing to confirm the absence of chronic infection at least once, especially if ALT is elevated.

\section{RECOMMENDATIONS}

7. Patients with confirmed HCV antibody should be evaluated using HCV RNA polymerase chain reaction (Class 1, Level C).

8. Individuals with positive HCV RNA tests should undergo HCV genotyping (Class 1, Level C).

9. Individuals with negative HCV RNA tests should undergo repeat testing at least once to confirm spontaneous clearance if liver enzyme levels are elevated (Class 1, Level C).

All individuals should also undergo screening for hepatitis A immunity (hepatitis A immunoglobulin G) and for hepatitis B (hepatitis B surface antigen, hepatitis B surface antibody and hepatitis B core antibody), and should be vaccinated if nonimmune or assessed for therapy if chronically infected with hepatitis B.

\section{RECOMMENDATIONS}

10. All patients should undergo screening for hepatitis A and B, and should be offered vaccination if nonimmune (Class 1 , Level C).

\section{Clinical assessment}

A detailed history and physical examination focused on signs and symptoms of liver disease is required. Features of advanced liver disease may include ascites, bulging flanks, peripheral edema, history of gastrointestinal bleeding and jaundice. Examination for splenomegaly, 
ascites, gynecomastia, spider nevi and other manifestations of ESLD should be performed.

\section{Laboratory monitoring}

Monitoring of complete blood count, liver enzyme panel including ALT and aspartate aminotransferase (AST), and markers of synthetic function (international normalized ratio, albumin and bilirubin) should be performed at baseline and can be monitored as a component of routine (every three to four months) laboratory testing in individuals undergoing ART. Testing should be performed at least twice per year in individuals not yet requiring antiretroviral therapy because HCV disease activity may prompt earlier consideration of ART (Section III).

Thrombocytopenia may be a marker of hypersplenism and advanced liver disease. Derangements in synthetic function also suggest advanced disease. Caution should be used when interpreting elevated bilirubin levels in patients receiving atazanavir-based regimens because atazanavir is associated with unconjugated hyperbilirubinemia, but elevated conjugated bilirubin indicates liver disease. Similarly, discordance between the absolute CD4 cell count and CD4 percentage (higher CD4 percentage than expected for the corresponding absolute value) in coinfected individuals may also suggest advanced disease. Among individuals enrolled in the CCC, 31\% had evidence of high discordance, which was associated with markers of ESLD (92). CD4 discordance has also been shown to correspond with advanced liver disease when assessed using transient elastography (TE) (93).

Additional baseline screening for other causes of chronic liver disease can be considered, including investigations for hemochromatosis (iron binding capacity with genetic testing if iron saturation exceeds 0.60 ), autoimmune hepatitis (including primary biliary cirrhosis where appropriate - antinuclear antibody, antismooth muscle antibody, antimitochondrial antibody and immunoglobulin levels), Wilson disease (ceruloplasmin) and alpha-1-antitrypsin deficiency. Attention to alcohol consumption is essential given the negative influence alcohol has on fibrosis progression.

\section{RECOMMENDATIONS}

11. Patients should be evaluated for other conditions that may result in or aggravate chronic liver disease (Table 4) (Class 1, Level C).

12. All patients should be counselled regarding alcohol reduction/ abstinence (Class 1, Level C).

Ultrasound of the liver at baseline should also be considered, and should be performed whenever thrombocytopenia is present.

Although liver enzyme elevations have traditionally been believed to reflect disease activity, it is now evident that HCV-infected individuals may develop fibrosis, and even cirrhosis, without significant elevations in liver enzyme levels. In a retrospective review of 326 liver biopsies performed in coinfected individuals between 1997 and 2003 at a European centre, approximately $25 \%$ of individuals with persistently normal ALT values were found to have at least stage 2 fibrosis (94). As such, ALT criteria alone should not determine treatment initiation in coinfected patients.

\section{Role of liver biopsy}

Liver biopsy has traditionally been regarded to be the gold standard of investigation for HCV-related disease progression in North America (95). The liver biopsy assesses both the degree of inflammatory activity and fibrosis, and may also reveal an alternative etiology of liver damage. Nonetheless, liver biopsies are invasive and difficult to repeat, often resulting in limited sample size and selection bias; therefore, they are, at best, an imperfect gold standard. In addition, results may be affected by tissue sampling and interpretation error (96). Results of the liver biopsy influence decisions regarding initiation of HCV therapy, with biopsy findings of more advanced fibrosis leading to more urgent initiation and minimal fibrosis scores potentially allowing for treatment deferral. However, a liver biopsy should not be considered mandatory for all individuals being considered for therapy, and decisions regarding biopsy should be conducted on a case-by-case basis. In circumstances in which the biopsy has led to a deferral of therapy, repeat biopsy in three years (compared with four to five years for monoinfected patients [97]) or evaluation of fibrosis using a noninvasive modality (see below) should be considered given concerns for progressive liver disease in coinfected patients.

\section{Noninvasive assessment of fibrosis - TE and laboratory markers}

TE (Fibroscan, Echosens, France) is a noninvasive technique involving measuring liver stiffness (with scores measured in $\mathrm{kPa}$ ) that serves as a marker of hepatic fibrosis (98). TE has been widely used in Europe and Canada for some time and was approved in the United States in April 2013. The Fibroscan received licensing approval in Canada in 2009. Use of TE for diagnosis of fibrosis has been established in a variety of chronic hepatic diseases, including HCV (99). Meta-analyses of TE compared with liver biopsy for the assessment of fibrosis have found relatively high concordance, with one meta-analysis finding that the mean area under the ROC curve for the diagnosis of significant fibrosis, severe fibrosis and cirrhosis were 0.84, 0.89 and 0.94, respectively (100). In another meta-analysis, the sensitivity and specificity for cut-offs for determining significant fibrosis were $71.9 \%$ and $82.4 \%$, respectively, and were $84.4 \%$ and $94.6 \%$, respectively, for cirrhosis (101).

TE has been validated in coinfected patients. In a cohort of 169 Spanish patients undergoing liver biopsy, the sensitivity and specificity of TE was established (102). To diagnose significant liver fibrosis, a cut-off value of $7.2 \mathrm{kPa}$ was associated with a positive predictive value of $88 \%$ and a negative predictive value of $75 \%$. To diagnose cirrhosis, a cut-off value of $14.6 \mathrm{kPa}$ was associated with a positive predictive value of $86 \%$ and a negative predictive value of $94 \%$ (102). Similarly, in an assessment of TE involving a North American cohort of injection drug users (the AIDS Linked to the IntraVenous Experience [ALIVE] cohort), including coinfected patients, $79 \%$ to $83 \%$ of individuals were correctly identified as having significant fibrosis and cirrhosis when TE was compared with liver biopsy (103).

Fibroscan may be limited by body habitus (obesity may impair the ability of the probe to accurately assess the liver) and may be falsely elevated in circumstances of significant hepatic inflammation (98). Of note, development of probes dedicated for use in obese patients may improve diagnostic value (104).

Novel use of noninvasive laboratory markers may aid in the assessment of fibrosis in coinfected patients. Use of the AST-to-platelet ratio index (APRI), calculated as ([AST/ULN]/platelet count $\left.\times 10^{9} / \mathrm{L}\right) \times 100$, has been validated in a Canadian cohort of coinfected patients $(105,106)$ in which an APRI score $>1.5$ was $100 \%$ specific and $52 \%$ sensitive for significant fibrosis compared with the gold standard of liver biopsy.

Other formulae for assessing fibrosis include the Fib-4 score (age [years] $\times$ AST $[\mathrm{IU} / \mathrm{L}] /$ platelet count [expressed as platelets $\left.\times 10^{9} / \mathrm{L}\right] \times$ $\left(\mathrm{ALT}^{1 / 2}[\mathrm{IU} / \mathrm{L}]\right)(107)$ and Fibrotest (LabCorp, USA) - a calculated algorithm of six serum tests (alfa-2-macroglobulin, apolipoprotein A1, haptoglobin, gamma-glutamyltransferase, ALT and bilirubin) and the age and sex of the patient $(108,109)$. These methods lack sensitivity for diagnosing fibrosis compared with TE $(110,111)$.

\section{Interleukin-28B testing}

Recent genome-wide association studies have identified a single nucleotide polymorphism located within the interleukin (IL) $28 \mathrm{~B}$ gene that is associated with both spontaneous clearance and response to pegylated interferon and ribavirin therapy $(112,113)$. Individuals who are homozygous for the CC allele have better outcomes compared with those with heterozygous CT or homozygous TT genotypes; however, the presence of a non-CC genotype does not rule out response to therapy. The role of IL28B polymorphisms in the era of DAAs has also not been well defined and, as such, routine testing to inform treatment decisions cannot be recommended at this time. 
TABLE 5

Virological response definitions while undergoing hepatitis $\mathrm{C}$ virus (HCV) therapy

\begin{tabular}{|c|c|c|c|}
\hline Definition & Time point & HCV RNA level & Comment \\
\hline RVR & Week 4 & Undetectable & RVR is highly predictive for SVR \\
\hline \multirow[t]{3}{*}{ EVR } & \multirow[t]{3}{*}{ Week 12} & Undetectable: Complete EVR & \multirow{3}{*}{$\begin{array}{l}\text { Lack of EVR is highly predictive for not } \\
\text { achieving SVR }\end{array}$} \\
\hline & & Detectable: Partial EVR (>2 $\log _{10}$ drop from baseline) & \\
\hline & & Detectable: Null responder $\left(<2 \log _{10}\right.$ drop from baseline) & \\
\hline Extended RVR & Week 4, 12 & Undetectable & $\begin{array}{l}\text { Highly predictive for achieving SVR with } \\
\text { telaprevir-based therapy }\end{array}$ \\
\hline Partial response & Week 24-48 & Detectable & Treatment failure \\
\hline End-of-treatment response & Week 48 & Undetectable & \\
\hline Relapser & Week 48-72 & Detectable & Treatment failure \\
\hline SVR - week 60 (SVR12) & Week 60 & Undetectable & Predicts SVR24 in monoinfected patients \\
\hline SVR - week 72 (SVR24) & Week 72 & Undetectable & Treatment success \\
\hline
\end{tabular}

EVR Early virological response; RVR Rapid virological response; SVR Sustained virological response; SVR12/24 SVR after 12 or 24 weeks of follow-up

Monitoring of patients with cirrhosis

Patients with confirmed cirrhosis should undergo additional monitoring for the development of complications such as HCC. Surveillance screening with regular ultrasounds (every six months) with or without use of serum alpha fetoprotein should be undertaken, as is the case in HIV-negative individuals with cirrhosis. Referral to a gastroenterologist for consideration of endoscopy to screen and/or monitor esophageal varices may also be indicated.

Ongoing monitoring for HCC is also advised in patients with cirrhosis who have achieved SVR with HCV therapy because the risk related to underlying cirrhosis may persist.

\section{RECOMMENDATIONS}

13. ALT criteria alone should not be used to determine the need for treatment initiation in coinfected patients (Class 2a, Level C).

14. Baseline abdominal ultrasound should be considered in all patients (Class 2a, Level B).

15. Baseline evaluation of liver fibrosis (eg, Fibroscan, Fibrotest, APRI) to determine the degree of hepatic fibrosis and urgency for HCV therapy is advised (Class 2a, Level B).

16. Evaluation of liver fibrosis with liver biopsy can be considered if noninvasive methods of determining fibrosis are not available or if alternative diagnoses are being considered.

17. Patients with evidence of underlying cirrhosis should be screened every six months for HCC using ultrasound (Class 1, Level B).

18. Patients with underlying cirrhosis should be considered for gastroscopy to screen for esophageal varices (Class 1, Level B).

\section{HCV THERAPY IN COINFECTED PATIENTS}

There is clear evidence that successful HCV treatment leads to reduced disease burden from HCV infection. Successful HCV treatment has, to date, been the most effective means of preventing liverrelated complications in the setting of HIV-HCV coinfection (114). Despite this, a minority of individuals have initiated treatment; only $1.1 \%$ (15 of 1360) initiated treatment for HCV from January 2000 to December 2004 in an inner-city cohort in British Columbia (115). In the CCC, $16 \%$ had been previously treated at the time of cohort enrollment baseline and 13\% initiated treatment follow-up (total $29 \%$ ). While low, this is consistent with treatment rates reported in the literature elsewhere in the world (116).

All coinfected patients should be assessed for HCV therapy. At present, therapy for $\mathrm{HCV}$ is determined by HCV genotype. Genotype 1 infections are treated with combination therapy including pegylated interferon, ribavirin and an orally administered NS3/4A PI (a class of HCV-specific DAAs). Presently, two formulations of pegylated interferon are available in Canada: pegylated interferon alfa-2a (Pegasys [Hoffmann-La Roche Ltd, Canada], dosed as $180 \mu \mathrm{g}$ subcutaneously once weekly) or pegylated interferon alfa-2b (Pegetron [Merck Canada Inc, Canada], dosed as $1.5 \mu \mathrm{g} / \mathrm{kg}$ subcutaneously once weekly). Other genotypes, including genotypes 2 , 3 and 4 , continue to receive pegylated interferon and ribavirin, with length of therapy for genotypes $2 / 3$ determined, in part, by virological response while on therapy and underlying fibrosis (see below). Classification of virological responses to therapy are presented in Table 5 .

\section{Preparation for HCV therapy}

Baseline laboratory determination of HCV status as outlined is necessary to evaluate HCV genotype and degree of hepatic fibrosis/disease.

Given the burden of comorbid conditions in the setting of coinfection, evaluation of factors, such as substance use/addictions, mental health, and housing and food security, is vital when preparing for HCV therapy. Substance use, lack of housing or lack of adequate food supply may limit the adherence to HCV therapy, with deleterious effects on treatment outcome. Underlying mental health conditions may be exacerbated by interferon-based therapy, and multidisciplinary follow-up is recommended.

Individuals considering HCV therapy should be assessed for potential contraindications to receipt of interferon and ribavirin, which remain a core component of current HCV therapy. Contraindications include:

- pregnancy;

- decompensated liver disease;

- autoimmune hepatitis;

- unstable depression/psychosis; and

- unstable coronary artery disease.

Individuals $>50$ years of age with history of hypertension, diabetes or previous retinopathy should undergo a baseline ophthalmology assessment because interferon therapy has been associated with exacerbation/new onset of retinopathy $(117,118)$.

When considering HCV therapy in injection drug user populations, concomitant use of harm-reduction strategies is necessary given the risk of potential reinfection if IDU resumes after successful therapy (119). Mathematical models suggest that HCV therapy in this population has the potential to reduce transmission within networks of injection drug user populations (120). Individuals who have previously undergone successful HCV therapy should be reevaluated if ALT elevation recurs to rule out reinfection.

In some regions, $\mathrm{HIV}$-HCV coinfected individuals face obstacles to engaging $\mathrm{HCV}$ care and initiating HCV antiviral therapy due to inadequate funding of $\mathrm{HCV}$ treatment programs and limitations placed on access to HCV antiviral therapy.

Adherence to HCV antiviral therapy is critical to achieving treatment success. The importance of this should be discussed with potential treatment candidates; potential obstacles to adherence should be 


\begin{tabular}{|c|c|c|}
\hline & Telaprevir & Boceprevir \\
\hline Naive patients & $75 \%$ versus $44 \%^{*}$ & $63 \%$ versus $38 \%{ }^{*}$ \\
\hline Naive with RVR & $92 \%$ (eRVR) & $88 \%$ (at week 4 of triple therapy) \\
\hline Naive/cirrhosis & $62 \%$ versus $33 \%$ & $52 \%$ versus $38 \%$ \\
\hline Previous relapser & $83 \%$ versus $24 \%$ & $75 \%$ versus $29 \%$ \\
\hline Partial responder & $59 \%$ versus $15 \%$ & $52 \%$ versus $7 \%$ \\
\hline Null responder & $29 \%$ versus $5 \%$ & $38 \%$ in a single-arm study \\
\hline
\end{tabular}

*When compared with standard pegylated interferon and ribavirin. eRVR Early rapid virological response (RVR). Data from references 121-124 and 213

identified and strategies to maximize adherence should be developed. Adherence should be monitored and reinforced throughout the entire course of treatment. If nonadherence is encountered and cannot be rapidly corrected while on therapy, therapy should be interrupted.

\section{RECOMMENDATIONS}

19. All coinfected patients should undergo evaluation for HCV therapy (Class 1, Level A).

20. Evaluation of factors such as substance use/addictions, mental health, and housing and food security is vital when preparing for HCV therapy (Class 1, Level B).

21. Addiction should not be considered to be an absolute exclusion criteria for HCV therapy.

22. Multidisciplinary care is recommended to optimally support patients as they progress through HCV work-up and treatment (Class 1, Level B).

23. A detailed assessment for interferon-based treatment contraindications is essential (Class 1, Level C).

24. Appropriate levels of funding for HCV treatment programs and removal of barriers to $\mathrm{HCV}$ antiviral therapy are necessary to optimize engagement in care and treatment outcomes (Class 1, Level C)

Timing of therapy initiation in individuals naive to both HIV and HCV therapy

Individuals presenting with evidence of advancing HIV infection (CD4 count $<500$ cells $/ \mu \mathrm{L}$ ) should be considered for initiation of ART as per current HIV guidelines (66-69). In individuals with CD4 count $\geq 500$ cells $/ \mu \mathrm{L}$, consideration should be given to early initiation of $\mathrm{HCV}$ therapy. Benefits of early HCV therapy include effects on HCVrelated liver disease progression, avoidance of drug-drug interactions and pill burden issues arising from concomitant ART and HCV therapy, and potential improvement in tolerability of future ART due to decrease in risk for ART-related hepatotoxicity (70). Individuals who cannot initiate early HCV therapy may be considered for early ART as described above (Section II Recommendation).

An additional consideration in individuals with relatively mild liver disease is the anticipated availability of either simpler once-daily DAAs or use of combination DAAs without the use of pegylated interferon, with potential for simpler, less toxic and more effective therapy. Individuals with early fibrosis and no HCV-related symptoms could, therefore, be counselled to defer therapy and undergo conservative monitoring with serial noninvasive methods of fibrosis assessment while awaiting studies of these agents in coinfected patients and eventual regulatory approval. Individuals with METAVIR stage 2 to 4 fibrosis should be considered for therapy with currently available agents.

\section{Genotype 1 treatment}

Current standard of care for genotype $1 \mathrm{HCV}$ monoinfected individuals consists of triple therapy with pegylated interferon, ribavirin and a PI
TABLE 7

Differences in administration and duration of therapy for telaprevir and boceprevir in hepatitis $\mathrm{C}$ monoinfected individuals

\begin{tabular}{|c|c|c|}
\hline & Telaprevir & Boceprevir \\
\hline Dose & $\begin{array}{l}750 \text { mg every } 8 \text { h/ } \\
1125 \text { mg twice daily }\end{array}$ & $800 \mathrm{mg}$ three times daily \\
\hline Food requirement & $\begin{array}{l}\text { Yes: meals should contain } \\
\text { at least } 9 \mathrm{~g} \text { of fat }\end{array}$ & Yes \\
\hline Lead-in phase & No & $\begin{array}{l}\text { Yes: } 4 \text { weeks of PegIFN/ } \\
\text { RBV first }\end{array}$ \\
\hline $\begin{array}{l}\text { Duration of protease } \\
\text { inhibitor }\end{array}$ & $\begin{array}{l}\text { First } 12 \text { weeks of } \\
\text { therapy only }\end{array}$ & $\begin{array}{l}\text { Response-dependent: } \\
24 \text { week minimum }\end{array}$ \\
\hline $\begin{array}{l}\text { Response-guided } \\
\text { therapy possible? }\end{array}$ & $\begin{array}{l}\text { Yes: } 58 \%-65 \% \text { naive/ } \\
\text { relapsers stop all } \\
\text { treatment at week } 24\end{array}$ & $\begin{array}{l}\text { Yes: } 44 \%-47 \% \text { of naive/ } \\
\text { experienced patients stop } \\
\text { at week } 28 / 36 \text {, } \\
\text { respectively }\end{array}$ \\
\hline
\end{tabular}

PegIFN/RBV Pegylated interferon/ribavirin

(boceprevir or telaprevir are the only PIs currently approved). Published phase III studies with both boceprevir and telaprevir in HCV monoinfected populations demonstrate markedly improved SVR rates compared with dual pegylated interferon plus ribavirin therapy in treatment-naive, previous relapser, previous partial responder and previous null responder populations $(121-124)$. Boceprevir has a short halflife and, thus, requires dosing every $8 \mathrm{~h}$. Telaprevir is also approved for dosing every $8 \mathrm{~h}$. However, data from a large randomized clinical trial involving treatment-naive monoinfected individuals indicate that telaprevir can be dosed twice daily with similar SVR rates and side effect profile (125). Absorption of both drugs is highly dependent on food; boceprevir bioavailability increases $60 \%$ when taken with food, regardless of meal type (126). Telaprevir should be taken with a meal or snack comprising at least $9 \mathrm{~g}$ and up to $20 \mathrm{~g}$ of fat (127). Tables 6 and 7 outline major differences between telaprevir and boceprevir.

Interim results from two phase II randomized comparative studies describing markedly improved SVR outcomes with triple therapy (containing pegylated interferon, ribavirin and a HCV PI) versus dual therapy with peginterferon plus ribavirin can guide antiviral therapy for HCV genotype 1 treatment-naive patients coinfected with HIV (Table 8) (128-131). There are no published studies at this time. The interim nature of these results and the relatively small sample sizes ( $\mathrm{n}<100$ for each) should be considered when evaluating virological response, relapse and adverse event results.

Boceprevir: In a randomized, double-blinded trial of pegylated interferon alfa-2b and ribavirin with or without boceprevir, SVR 12 weeks post-therapy (SVR12) was achieved in $62.5 \%$ of triple therapy recipients $(n=64)$ versus $26.5 \%$ of pegylated interferon alfa- $2 b$ and ribavirintreated study participants $(\mathrm{n}=34)(128,130)$ (Figure 1$)$. All patients were on ART with stable HIV suppression. Antiretroviral regimens allowed in this study consisted of a PI boosted by ritonavir, raltegravir or maraviroc, in conjunction with two nucleoside inhibitors other than zidovudine, stavudine or didanosine. Most participants were on atazanavir-, lopinavir- or darunavir-based regimens. NNRTI-based regimens were not allowed in this protocol. Only five of 98 participants were cirrhotic. Approximately two-thirds were infected with genotype $1 \mathrm{a}$, which is a negative predictor of HCV PI efficacy. All participants received 48 weeks of therapy. A four-week lead-in phase with pegylated interferon alfa- $2 \mathrm{~b}$ and ribavirin was used in this study followed by a fixed duration of 44 weeks of boceprevir $800 \mathrm{mg}$ every $8 \mathrm{~h}$ or placebo. A weight-based approach to ribavirin dosing was used (600 mg to $1400 \mathrm{mg}$ per day divided twice daily). Stopping rules for virological futility were similar to those previously used for pegylated interferon alfa-2b and ribavirin therapy $\left(<2 \log _{10}\right.$ reduction in HCV RNA from baseline at week 12 of therapy or detectable HCV RNA at week 24) (Table 9), which differ from the current criteria for futility for boceprevir-containing HCV antiviral treatment in HCV monoinfected individuals. 
TABLE 8

Treatment protocols for hepatitis C (HCV) genotype 1 in HIV-HCV coinfection

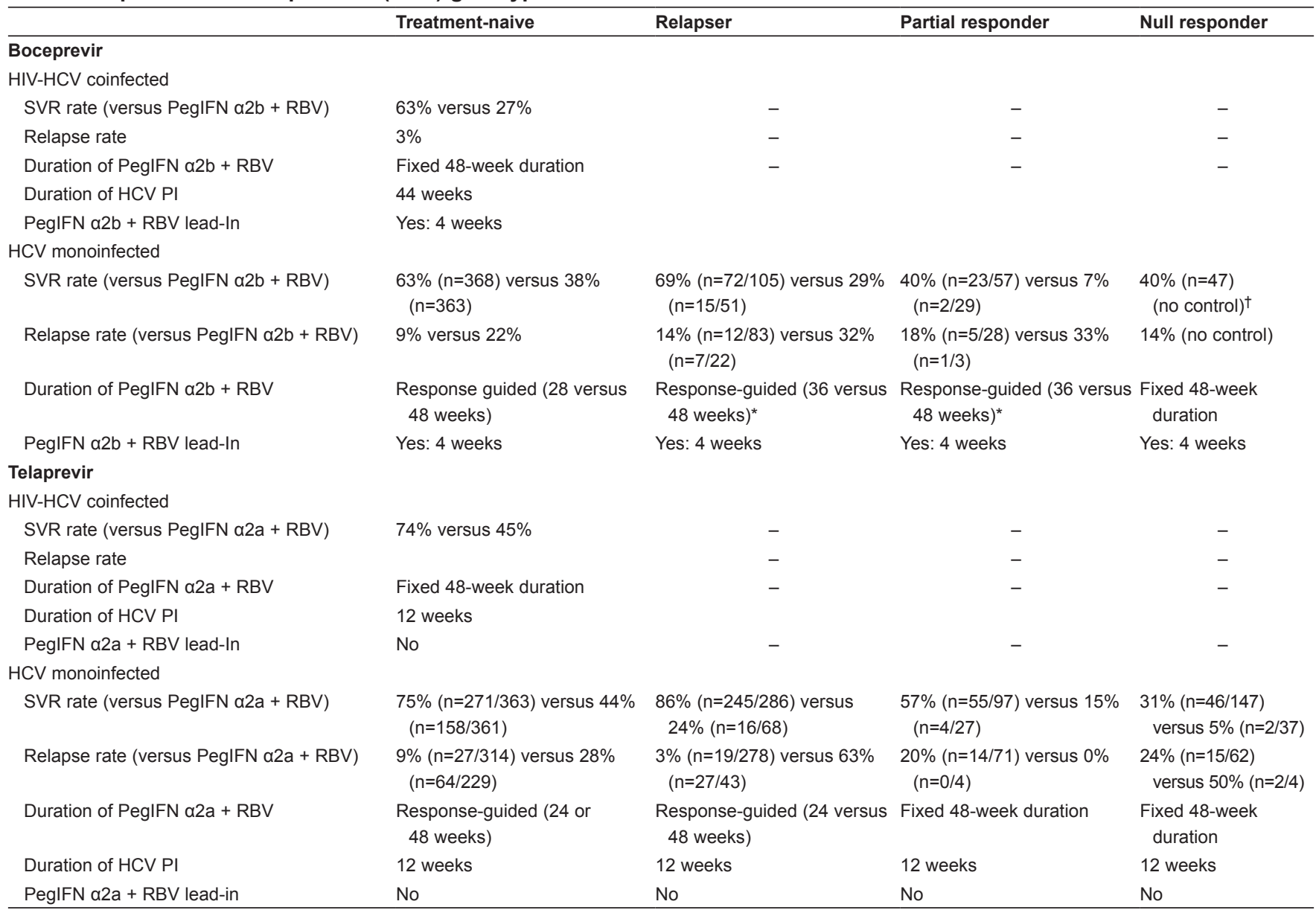

*If cirrhotic, then 48 weeks fixed duration, fInterim results from rollover study (132). PegIFN a2a Pegylated interferon alfa-2a; PI Protease inhibitor; RBV Ribavirin; SVR Sustained virological response

Telaprevir: In a randomized, double-blinded clinical trial, pegylated interferon alfa-2a and ribavirin with or without telaprevir was assessed in HIV-infected patients not on ART with CD4 lymphocyte counts $>500$ cells $/ \mu \mathrm{L}(\mathrm{n}=22$, part $\mathrm{A})$ and in patients receiving suppressive ART ( $\mathrm{n}=38$, part B) (Figure 1) (129). Antiretroviral regimens allowed in the study consisted of either efavirenz or atazanavir boosted with ritonavir, in combination with a tenofovir/emtricitabine or tenofovir/lamivudine backbone. Only two patients were cirrhotic and $43 \%$ to $80 \%$ of participants in the randomization groups were infected with genotype 1a. Most participants received a ribavirin dose of $800 \mathrm{mg}$ per day based on the United States product monograph for pegylated interferon alfa-2a in HIV-HCV coinfected individuals. A small number of participants from Germany and France received higher ribavirin doses as per the product monographs in these countries. Recipients received 48 weeks of fixed-duration pegylated interferon alfa-2a and ribavirin. Patients were dosed with either 12 weeks of telaprevir $750 \mathrm{mg}$ every $8 \mathrm{~h}(1125 \mathrm{mg}$ every $8 \mathrm{~h}$ for patients receiving efavirenz due to anticipated drug-drug interactions) or placebo. No lead-in was used. An overall SVR12 of $74 \%$ $(n=38)$ was reported in triple therapy recipients compared with $45 \%$ in pegylated interferon alfa-2a and ribavirin recipients $(n=22)(129)$. These data have subsequently been updated with release of SVR results at 24 weeks post-therapy (131). Overall, 74\% of patients receiving telaprevir achieved an SVR compared with $45 \%$ of those receiving pegylated interferon and ribavirin. Overall relapse rates were $3 \%$ for those receiving telaprevir versus $15 \%$ for those receiving pegylated interferon and ribavirin. These SVR rates were similar

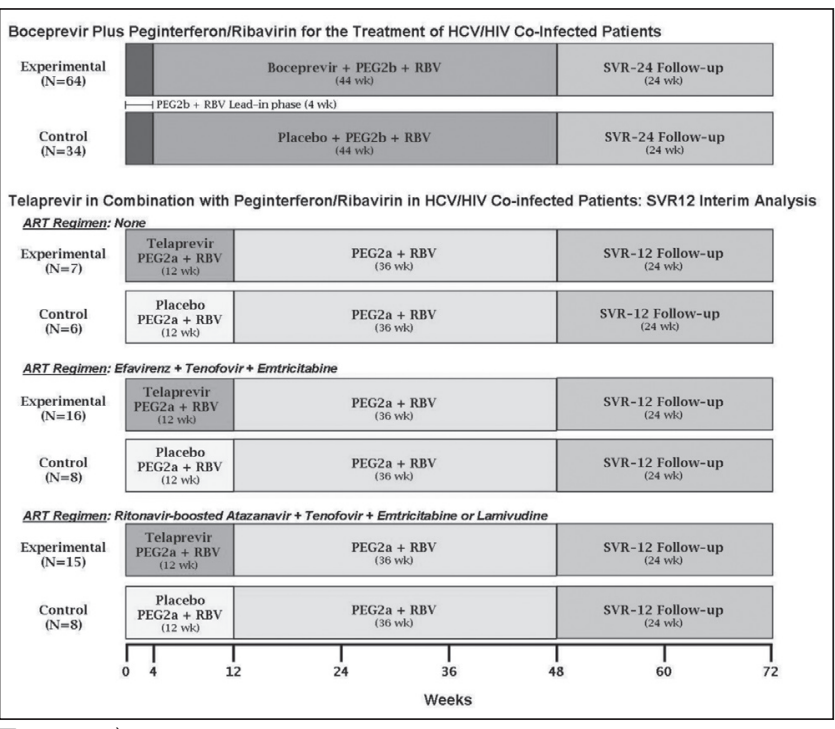

Figure 1) Study designs for hepatitis $\mathrm{C}$ virus (HCV) protease inhibitors in HIV-HCV coinfection. ART Antiretroviral therapy; PEG2a Pegylated interferon alfa-2a; RBV Ribavirin; SVR Sustained virological response; SVR12/24 SVR after 12 and 24 weeks' follow-up

between those on ART and those who were not. SVR rates were comparable between atazanavir/ritonavir recipients and efavirenz recipients in both randomization groups. 
TABLE 9

Stopping rules for protease inhibitor-containing hepatitis C (HCV) antiviral therapy in HIV-HCV coinfection

\begin{tabular}{|c|c|c|c|c|}
\hline & \multicolumn{2}{|c|}{ Boceprevir } & \multicolumn{2}{|c|}{ Telaprevir } \\
\hline & HIV-HCV coinfection* & HCV monoinfection ${ }^{\dagger}$ & HIV-HCV coinfection* & HCV monoinfection ${ }^{\ddagger}$ \\
\hline Week 4 & & & HCV RNA >1000 IU/mL§ & HCV RNA >1000 IU/mL§ \\
\hline Week 8 & & & HCV RNA >1000 IU/mL§ & \\
\hline \multirow[t]{4}{*}{ Week 12} & Detectable HCV RNA, & HCV RNA > $100 \mathrm{IU} / \mathrm{mL}^{\ddagger}$ & Telaprevir patients: & HCV RNA >1000 IU/mL§ \\
\hline & $<2 \log _{10}$ decline & & $\begin{array}{l}\text { HCV RNA } \leq 1000 \mathrm{IU} / \mathrm{mL}^{\S} \text { (at weeks } \\
4 \text { and } 8 \text { ), }>1000 \mathrm{IU} / \mathrm{mL}^{\S} \\
\text { (at week 12) }\end{array}$ & \\
\hline & & & All other patients: & \\
\hline & & & HCV RNA $<2 \log _{10}$ decline & \\
\hline Week 24 & HCV RNA $\geq$ LLOQ & Detectable HCV RNA & Detectable HCV RNA & Detectable HCV RNA \\
\hline
\end{tabular}

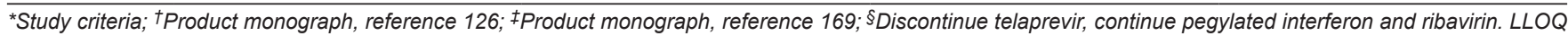
Lower limit of quantitation

Stopping rules were similar to those recommended for HCV monoinfected individuals: HCV RNA $>1000 \mathrm{IU} / \mathrm{mL}$ or $<2 \log _{10}$ reduction at week 12 of therapy or detectable HCV RNA at week 24 (Table 9).

There is limited research evaluating triple therapy in cirrhotic HIV-HCV coinfected individuals because few cirrhotic patients were enrolled in the above-described treatment-naive studies. HCV monoinfected cirrhotic patients achieved SVR rates in the range of $60 \%$ with triple therapy (Table 7) $(122,124)$.

\section{RECOMMENDATIONS}

25. Genotype 1-infected HIV-HCV coinfected patients should be treated with either boceprevir or telaprevir in combination with pegylated interferon and ribavirin (Class 1, Level A).

26. Telaprevir should be used for the first 12 weeks, while boceprevir should begin after a four-week lead-in of pegylated interferon and ribavirin and continue for the remainder of therapy (Class 1, Level A).

27. At this time, a full 48-week course of pegylated interferon and ribavirin is recommended because there is no current evidence regarding response-guided therapy in coinfected patients (Class 1, Level C).

28. Standard stopping rules at weeks 4,12 and 24 (telaprevir), or weeks 8,12 and 24 (boceprevir) developed for monoinfection should be applied to the HIV-HCV coinfection context (Class 1, Level C).

\section{Retreatment of coinfected patients}

There are currently no published data to guide triple therapy in previous genotype $1 \mathrm{HCV}$ treatment-experienced HIV-HCV coinfected individuals, although interim data on the use of both boceprevir and telaprevir have been presented in abstract form.

Data in HCV monoinfected patients demonstrate superior SVR rates in previous relapsers, partial responders and null responders receiving a PI plus pegylated interferon and ribavirin compared with pegylated interferon and ribavirin alone $(122,124,132)$ (Table 6).

In two parallel, open-label, single-arm phase II studies (ANRS HC26 and HC27), HCV treatment-experienced HIV-HCV coinfected patients received either telaprevir or boceprevir therapy $(133,134)$. Patients were included if they had stable CD4 cell counts $>200$ cells $/ \mu L(C D 4 \%$ $>15 \%$ ) with suppressed viral load on atazanavir/ritonavir- or raltegravirbased regimens (efavirenz was allowed in patients in the telaprevir trial). Both trials made use of a four-week lead-in of pegylated interferon and ribavirin. In ANRS HC26, participants $(n=68)$ received 12 weeks of triple therapy following the lead-in, with additional pegylated interferon and ribavirin for a total of 48 or 72 weeks in a response-guided fashion dependent on results of the week 8 (week 4 of triple therapy) outcome (133). In ANRS HC27 ( $n=64)$, the lead-in phase was followed by 44 weeks of triple therapy with boceprevir (134). Those without a week 8 rapid virological response (RVR) would receive an additional 24 weeks (total 72 weeks) of pegylated interferon. Interim results reveal high rates of early virological response (EVR) (measured in these trials at week 16 [EVR16] of therapy). In those receiving telaprevir, the overall EVR16 was $88 \%$. There were no significant differences observed in terms of ART regimen, degree of fibrosis or previous response to therapy, with $85 \%$ response in previous relapers, $100 \%$ in previous partial responders and $86 \%$ in null responders. For subjects receiving boceprevir, overall EVR16 was $63 \%$. In this study, a graduated response was observed based on previous response, with 90\%, 61\% and 38\% EVR16 observed in previous relapsers, nonresponders and null responders, respectively.

It is reasonable to assume that these encouraging interim findings will result in similar SVR outcomes to those observed in trials involving monoinfected patients, with highest SVR rates in previous relapsers (higher than treatment-naive patients), intermediate SVR rates in previous partial responders and the lowest SVR rates in previous null responders, but it is unclear whether coinfected patients will achieve similar outcomes. Cirrhotic patients with previous null response to pegylated interferon and ribavirin achieved very low SVR rates in HCV monoinfected studies. In the REALIZE study, only 14\% (seven of 50) of cirrhotic patients with a previous null response achieved SVR when treated with telaprevir plus peginterferon and ribavirin (124). There are no data to guide treatment of HIV-HCV coinfected patients with cirrhosis and a history of previous null response to pegylated interferon and ribavirin because these patients were excluded in the ANRS trials. However, a similarly low SVR rate would be anticipated with triple therapy.

The need to optimize additional factors such as CD4 cell count, steatohepatitis or insulin resistance in individuals undergoing retreatment is unclear in the setting of retreatment with HCV PI-containing regimens. Previous studies have suggested that insulin resistance may compromise retreatment with pegylated interferon and ribavirin alone (135). As in the case of treatment-naive individuals, in patients being considered for retreatment, individuals with relatively stable mild hepatic disease may be followed with conservative management pending availability of combination DAA-based therapies. Individuals with more advanced liver disease may need to be retreated with currently available DAAs to prevent further disease progression. Retreatment in individuals with previous history of decompensated disease should be undertaken only in experienced centres with access to transplant services due to the risk of treatment-related decompensation.

\section{RECOMMENDATION}

29. No published SVR data currently exist for retreatment of genotype 1 null responders, partial responders or previous relapsers in the setting of HIV coinfection. However, retreatment following protocols developed for monoinfected patients can be considered (Class 2b, Level C).

Novel DAAs for genotype 1 coinfected patients

Preliminary interim results of a phase III single arm study of the use of the once-daily HCV PI simeprevir in combination with pegylated 
interferon and ribavirin have been presented (the TMC435-C212 study) (136). This trial enrolled treatment-naive individuals $(n=50)$, previous relapsers $(n=14)$, partial responders $(n=10)$ and null responders $(n=28)$ to receive 12 weeks of triple therapy with simeprevir, pegylated interferon and ribavirin followed by either response-guided pegylated interferon/ribavirin ( 24 or 48 weeks) in naive/relapsers, or 48 weeks total of pegylated interferon/ribavirin in treatment-experienced patients or those with cirrhosis. Acceptable antiretrovirals included raltegravir, rilpivirine and maraviroc in addition to standard NRTI backbones. Among treatment naive/relapsers, the combined SVR12 was $75 \%$, and $88 \%$ of those eligible for response-guided therapy were able to stop after 24 weeks with SVR12 of $75 \%$. No SVR data are currently available for partial and null responder patients, but in those with on-treatment virological failure, $37.5 \%$ were previous null responders.

At the present time, no recommendations can be made regarding simeprevir use in coinfected patients in Canada. Simprevir is not currently approved but has been submitted for regulatory review in the United States, Canada and Europe.

\section{HCV therapy for nongenotype 1 infection}

Genotype 2 and 3: The treatment of choice for HCV genotypes other than genotype 1 is dual therapy with pegylated interferon in combination with ribavirin. There are HIV-HCV coinfection data with significant numbers of patients with genotype 3 , moderate numbers with genotype 4 , limited numbers with genotype 2 and no data for genotypes 5 and $6(137-139)$.

For HCV genotypes 2 and 3, the dose of ribavirin and the treatment duration in the HIV-coinfected population are controversial. In HCV monoinfection, two randomized trials found no difference in SVR rates with 24 versus 48 weeks of therapy $(140,141)$. Another randomized trial involving HCV monoinfected patients demonstrated higher SVR rates with 24 weeks than 16 weeks of therapy, even among those who achieved a RVR (142). Two randomized trials found no significant difference in SVR rates in monoinfected patients receiving an $800 \mathrm{mg}$ daily dose of ribavirin compared with those receiving weight-based dosing $(140,141)$. On the basis of the above studies, HCV monoinfected patients are treated for 24 weeks and $800 \mathrm{mg} /$ day ribavirin.

In genotype 2 or $3 \mathrm{HIV}-\mathrm{HCV}$ coinfected patients, treatment with pegylated interferon and ribavirin for 24 weeks using a ribavirin dose of $800 \mathrm{mg} /$ day is associated with relapse rates of $32 \%$ to $40 \%$ (143-145). In contrast, treatment with pegylated interferon and ribavirin for 24 weeks using weight-based dosing is associated with a relapse rate of $9 \%$ to $15 \%(146,147)$. This is comparable with relapse rates of $10 \%$ to $16 \%$ observed with 24 -week pegylated interferon/ ribavirin therapy in the genotype 2 or 3 monoinfected populations $(140,142,148)$. The probable explanation for the lower relapse rates observed with weight-based dosing in the HIV-coinfected population is the substantially higher rate of RVR achieved compated with dosing at $800 \mathrm{mg} /$ day. In a large randomized trial of pegylated interferon and ribavirin compared with standard interferon-based regimens (the APRICOT trial [138]), in which patients received ribavirin 800 mg daily, only $37 \%$ of genotype 2 and 3 patients achieved RVR. In contrast, in a subsequent trial conducted in Spain (the PRESCO trial [139]), in which patients received ribavirin $1000 \mathrm{mg}$ daily if they weighed $<75 \mathrm{~kg}$ and $1200 \mathrm{mg}$ daily if they weighed $\geq 75 \mathrm{~kg}$, RVR rates were $67 \%$. Treating HIV-HCV genotype 2 and 3 coinfected patients with pegylated interferon/ribavirin for 48 weeks is associated with low relapse rates of $3 \%$ to $13 \%$, regardless of whether ribavirin is dosed at $800 \mathrm{mg}$ or is weight-based (137-139). Overall, the data support current international guidelines, which recommend weightbased ribavirin dosing for coinfected individuals with genotype 2 or 3 infection, a 24-week treatment duration in those who achieve RVR, and a 48-week treatment duration in those without RVR (Figure 2) (149). Additional consideration should be given to factors, such as degree of underlying fibrosis, that have been associated with decreased response, and longer duration of therapy in these individuals may be warranted.

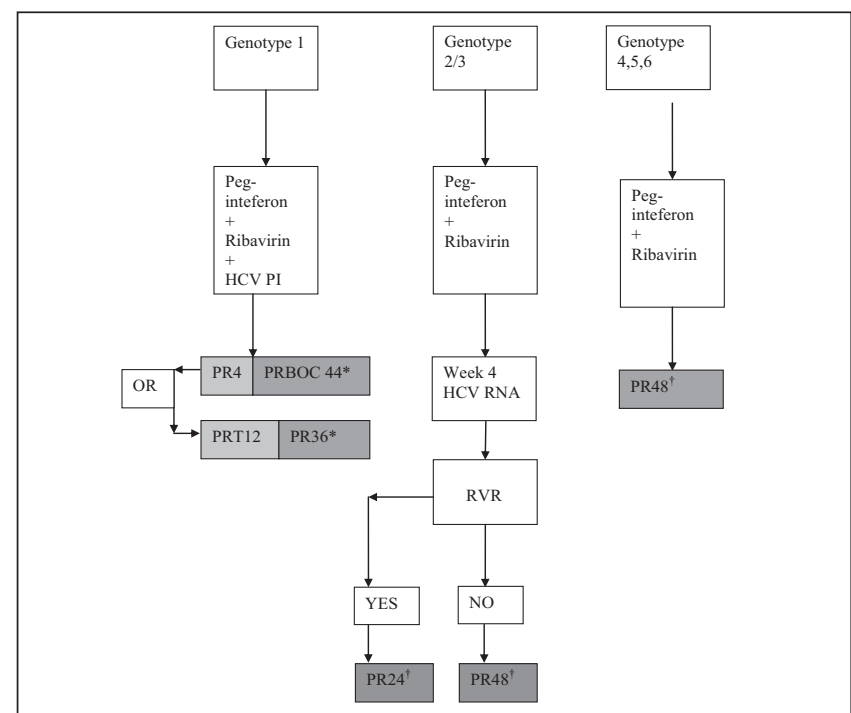

Figure 2) Treatment algorithms for coinfected patients. *Standard stopping rules apply (telaprevir [T]: HCV RNA $>100 \mathrm{IU} / \mathrm{mL}$ at week 4 and 12, detectable at week 24; boceprevir [BOC]: HCV RNA >1000 IU/mL at week 12, detectable at week 24); †Standard stopping rules apply: lack of early virological response at week 12, detectable hepatitis C virus (HCV) RNA at week 24.4, 12, 24, 48 refer to weeks of therapy; PI Protease inhibitor; PR Pegylated interferon/ribavirin; RVR Rapid virological response (undetectable HCV RNA)

There are limited data regarding retreatment in individuals with genotypes 2 or 3 . If flat-dose ribavirin and/or short treatment duration had initially been used, consideration may be given to retreatment, but no precise estimates of SVR in coinfected patients are available.

At present, boceprevir and telaprevir are not believed to have significant activity against genotypes 2 and 3 , and there are currently no data available regarding novel DAAs in genotypes 2 and 3 in HIVHCV coinfected patients.

Genotypes 4 to 6: For these genotypes, the traditional stopping rules for dual therapy apply, ie, failure to achieve at least a $2 \log _{10}$ decline in HCV RNA from baseline at week 12 of therapy or detectable HCV RNA at week 24 of therapy. For genotype 4, weight-based dosing of ribavirin is recommended, and the treatment duration is 48 weeks. There are no data regarding the use of DAAs in genotype 4 coinfected patients currently available.

\section{RECOMMENDATION}

30. For genotypes 2 and 3, weight-based ribavirin dosing, a 24-week treatment duration in those who achieve RVR, and a 48-week treatment duration in those without RVR or in those with significant fibrosis is recommended (Class 1, Level A).

\section{Treatment of acute HCV infection in coinfected patients}

Early studies with standard interferon alpha demonstrated high rates of virological response to therapy for acute HCV infection (150). With the advent of widespread recognition of sexual transmission of $\mathrm{HCV}$ in MSM populations, treatment for acute HCV is an increasingly common phenomenon (151). Although small studies have the use of nonribavirin-containing regimens, SVR rates with this approach have been diminished, and the European NEAT consensus panel on the management of acute HCV currently recommends standard doses of pegylated interferon and weight-based ribavirin therapy for treatment of acute HCV (41). In cases in which an RVR is achieved, 24 weeks of therapy are recommended, with full 48-week therapy for those without RVR (41). Outcomes for those treated within 12 to 24 weeks of acquisition of HCV are higher than if therapy is delayed for $>1$ year (152, 153). 
TABLE 10

Drug-drug interactions among antiretroviral agents, and telaprevir and boceprevir

\begin{tabular}{|c|c|c|}
\hline Antiretroviral agent & Boceprevir & Telaprevir \\
\hline \multicolumn{3}{|c|}{ Non-nucleoside reverse transcriptase inhibitors } \\
\hline Efavirenz & $\begin{array}{l}44 \% \downarrow \text { Cmin, } 19 \% \downarrow \text { AUC of boceprevir (183). } \\
\text { Avoid combination (126) }\end{array}$ & $\begin{array}{l}47 \% \downarrow \text { Cmin of telaprevir (214); consider } \uparrow \text { telaprevir dose to } \\
1125 \mathrm{mg} \text { every } 8 \mathrm{~h} \text { with efavirenz (172) }\end{array}$ \\
\hline Etravirine & $\begin{array}{l}29 \% \downarrow \text { Cmin, 23\% } \downarrow \text { AUC of etravirine. Clinical relevance } \\
\text { unclear (175) }\end{array}$ & $\begin{array}{l}\text { No clinically significant changes in either drug. No dose } \\
\text { adjustment required (173) }\end{array}$ \\
\hline Rilpivirine & $\begin{array}{l}\uparrow 39 \% \text { AUC, } \uparrow 15 \% \text { Cmax, } \uparrow 10 \% \text { Cmin of rilpivirine, not } \\
\text { considered clinically significant. No dose adjustment required } \\
\text { (176) }\end{array}$ & $\begin{array}{l}\uparrow 78 \% \text { AUC, } \uparrow 49 \% \text { Cmax, } \uparrow 93 \% \text { Cmin of rilpivirine, not } \\
\text { considered clinically significant. No dose adjustment required } \\
\text { (173) }\end{array}$ \\
\hline
\end{tabular}

Protease inhibitors

Atazanavir/ritonavir

Darunavir/ritonavir

Fosamprenavir/ritonavir

Lopinavir/ritonavir

Integrase inhibitors

Raltegravir

Reverse transcriptase inhibitors

Tenofovir

No clinically significant changes in either drug. No dose adjustment required (183)

$49 \% \downarrow$ Ctrough, 35\% $\downarrow$ AUC of atazanavir (170). Avoid combination

$59 \% \downarrow$ Ctrough, 44\% $\downarrow$ AUC of darunavir and 32\% $\downarrow$ boceprevir (170). Avoid combination No data

$43 \% \downarrow$ Ctrough, 34\% $\downarrow$ AUC of lopinavir and $45 \% \downarrow$ boceprevir (170). Avoid combination

No clinically significant changes in either drug. No dose adjustment required (177)

\section{$\uparrow$ Increase; $\downarrow$ Decrease; AUC Area under the curve; Cmax Maximum plasm \\ Ctrough Minimum plasma concentration immediately before the next dose}

Drug-drug interactions between antiretrovirals and HCV therapeutic agents

Didanosine, stavudine and zidovudine should be avoided with pegylated interferon and ribavirin because of increased risks of mitochondrial toxicity and anemia $(154,155)$. It is important to achieve adequate ribavirin trough levels via weight-based dosing $(154,156)$. Although some controversy exists as to whether concomitant abacavir diminishes ribavirin activity, larger cohort studies have not demonstrated diminished SVR (157-161). In addition, recent in vitro studies have demonstrated no such effect $(162,163)$. There is sufficient evidence to recommend continued use of this agent during HCV therapy with weight-based ribavirin dosing (164).

\section{Drug-drug interactions of DAAs}

The potential for interactions between HCV PIs and other drug classes is high due to the pharmacological characteristics of these HCV agents, particularly in the context of earlier ART initiation, the aging HIV population and need for management of comorbidities (165-167).

Boceprevir and telaprevir are substrates and inhibitors of cytochrome P450 (CYP450) 3A4 (CYP3A4). Both agents also inhibit P-glycoprotein, and telaprevir may inhibit renal transporters. Similarly, HIV PIs and NNRTIs are substrates and inhibitors or inducers of numerous CYP450 hepatic enzymes and transporters. The CCR5 inhibitor maraviroc is a CYP3A4 substrate but does not exert inhibiting or inducing effects on the P450 system. Therefore, there is a high potential for drug interactions in the coinfected population, particularly if simultaneous treatment of HCV and HIV is required.

Negative consequences of drug interactions include HIV and HCV viral breakthrough and development of resistance, suboptimal disease/ symptom management, or drug toxicities and possible nonadherence (168).

A summary of potential and demonstrated pharmacokinetic interactions between antiretroviral agents and DAAs is presented in Table 10. Negative two-way pharmacokinetic interactions have been observed in healthy volunteers between both boceprevir and telaprevir, and ritonavir-boosted PIs, with significant reductions in exposures of HCV agents and HIV PIs. Therefore, telaprevir should not be coadministered with ritonavir-boosted darunavir, fosamprenavir or lopinavir (169), and boceprevir is not recommended for use with ritonavir-boosted atazanavir, darunavir or lopinavir (170). It is worth noting that in the trial of boceprevir in coinfected patients, use of these PI agents was allowed, with no obvious rebound in HIV viral load (130). Recent case reports support this finding in patients with full virological suppression, and the potential increase in HIV PI levels in advanced liver disease as well as the anti-HIV activity of interferon may overcome negative interactions (171).

Telaprevir should be used at a higher dose (1125 mg every 8 h) with efavirenz (172). Dose adjustment with etravirine or rilpivirine is not required based on healthy volunteer data (173). In contrast, boceprevir concentrations are significantly reduced in the presence of efavirenz. This combination should be avoided (174). Etravirine concentrations are reduced in the presence of boceprevir but the clinical significance is uncertain. Therefore, recommendations pertaining to coadministration cannot be made (175). Recent data in healthy volunteers did not demonstrate significant interactions between rilpivirine and boceprevir, and concomitant therapy may be possible (176). Rilpivirine was safely coadministered with simeprevir in the TMC435-C212 study (138).

Raltegravir is not a CYP450 substrate, inducer or inhibitor, and may be used with both HCV PIs without dosage adjustment (177179). Underlying HIV resistance mutations may compromise HIVsuppression if individuals are switched from a robust PI-based regimen to raltegravir to accommodate DAA use. Regimen switches of this nature must take into account previous HIV therapies (180). Of note, the integrase inhibitor elvitegravir is a CYP3A4 substrate, and is coformulated with the pharmacokinetic booster cobicistat. There is potential for interaction with boceprevir and telaprevir based on pharmacokinetic properties; therefore, coadministration should be avoided until additional data are available (181). Dolutegravir is an integrase inhibitor in late-stage development. Similar to raltegravir, it is not a P450 substrate, inducer or inhibitor, and may be used with both boceprevir and telaprevir without dosage adjustment (182).

Tenofovir is eliminated renally. In healthy volunteer studies, peak plasma concentration of tenofovir was increased in the presence of boceprevir (183) and tenofovir area under the curve was increased in 
TABLE 11

Contraindicated medications arising from drug-drug interactions with boceprevir (BOC) and telaprevir (TVR)

\begin{tabular}{|c|c|c|}
\hline Medication & Contraindicated & Potential clinical impact \\
\hline Aldosterone antagonist & Eplerenone (TVR) & Hyperkalemia \\
\hline Alpha-1-adrenoreceptor antagonist & Alfuzosin & Hypotension, cardiac arrhythmia \\
\hline Antiarrhythmics & Amiodarone, quinidine, propafenone, flecainide (TVR) & Serious/life-threatening cardiac arrhythmia \\
\hline Anticonvulsants & Carbamazepine, phenytoin, phenobarbital (BOC) & Loss of HCV virological response \\
\hline Antihistamines & Astemizole, terfenadine (TVR) & Serious/life-threatening cardiac arrhythmia \\
\hline Antimycobacterials & Rifampin & Loss of HCV virological response \\
\hline Benzodiazepines & Oral midazolam, triazolam & Increased sedation or respiratory depression \\
\hline Ergot derivatives & $\begin{array}{l}\text { Dihydroergotamine, ergonovine, ergotamine, } \\
\text { methylergonovine }\end{array}$ & $\begin{array}{l}\text { Acute ergot toxicity characterized by peripheral } \\
\text { vasospasm or ischemia }\end{array}$ \\
\hline Gastrointestinal motility agent & Cisapride & Serious/life-threatening cardiac arrhythmia \\
\hline Herbal products & St John's wort & Loss of HCV virological response \\
\hline HMG-CoA reductase inhibitors & Lovastatin, simvastatin, atorvastatin (TVR) & Myopathy including rhabdomyolysis \\
\hline Neuroleptic & Pimozide & Serious/life-threatening cardiac arrhythmia \\
\hline Oral contraceptives & Drospirenone (BOC) & Hyperkalemia \\
\hline Phosphodiesterase type 5 inhibitors & Sildenafil, tadalafil (BOC), vardenafil (TVR) & $\begin{array}{l}\text { Visual abnormalities, hypotension, prolonged erection, } \\
\text { syncope }\end{array}$ \\
\hline Triptans & Eletriptan & $\begin{array}{l}\text { Coronary artery vasospasm, myocardial infarction, } \\
\text { ventricular tachycardia, ventricular fibrillation }\end{array}$ \\
\hline
\end{tabular}

HCV Hepatitis C virus; HMG-CoA 5-hydroxy-3-methylglutaryl coenzyme A reductase inhibitors (statins)

the presence of telaprevir (184). These changes are not considered to be clinically relevant, and tenofovir may be coadministered with both boceprevir and telaprevir.

Maraviroc is a CYP3A4 substrate, but does not exert enzyme inhibiting or inducing effects itself. Maraviroc should be dosed at $150 \mathrm{mg}$ twice daily when given concomitantly with either boceprevir or telaprevir (185).

\section{RECOMMENDATIONS}

31. Careful attention to drug-drug interactions between $\mathrm{HCV}$ antivirals and concurrently administered HIV and non-HIV medications is critical to avoid viral breakthrough of either HIV or HCV, development of resistance, suboptimal disease/symptom management and drug toxicities (Class 1, Level C).

32. Use of zidovudine, stavudine and didanosine regimens should be avoided in coinfected patients being considered for $\mathrm{HCV}$ therapy (Class 1, Level C).

33. For individuals with genotype 1 infection initiating $\mathrm{HCV}$ therapy, use of raltegravir-based regimens (boceprevir and telaprevir) or atazanavir/ritonavir (telaprevir) are first-line antiretroviral options (Class 2b, Level B). Rilpivirine-based therapy may be an acceptable first-line regimen (telaprevir, boceprevir).

34. For individuals with genotype 1 infection initiating HCV therapy, use of efavirenz (telaprevir with dose adjustment), or etravirine (acceptable with telaprevir but clinical implications of a potential interaction with boceprevir remain uncertain) and maraviroc (telaprevir, boceprevir) may be considered (Class 2b, Level B).

35. For individuals with genotype 1 infection initiating $\mathrm{HCV}$ therapy, switching from alternative regimens to an acceptable regimen as listed above can be considered if HIV treatment history and resistance profile permits such a switch.

36. For patients with HIV multidrug resistance who are well controlled on nonpreferred ART regimens, initiation of triple therapy, including DAAs, may be considered in consultation with an expert physician and pharmacist with experience in managing HIV and HCV drug interactions.

Interactions between DAAs and other drug classes

Many common drugs from multiple different classes are at risk of drug interactions with DAAs. (Table 11). The product monographs of boceprevir and telaprevir provide a list of drugs with known or potential CYP3A4 interactions $(126,169)$. Examples of interacting drug classes include benzodiazepines (eg, midazolam), 5-hydroxy-3-methylglutarylcoenzyme A reductase inhibitors (statins), macrolides, rifamycins (eg, rifampin), anticonvulsants, antiarrhythmics, psychotropics, antifungals, erectile dysfunction drugs, antipsychotics, inhaled corticosteroids, calcium channel blockers, immunosuppressants and others $(126,166,169,186)$. The management of these complex medication combinations requires expert knowledge. Substitution or safe discontinuation of the interacting drug can be attempted after careful evaluation of the benefit-risk ratio.

Methadone has the potential to interact with DAAs because it is metabolized by CYP2C19 and 3A4. The coadministration of methadone and telaprevir was shown to result in a $21 \%$ decrease of the active enantiomer R-methadone exposure (187). However, free concentrations of the active enantiomer $\mathrm{R}$-methadone were unaffected and, therefore, no dose adjustment is necessary. Buprenorphine pharmacokinetics are not affected by telaprevir and it is safe for coadministration (188). Boceprevir was studied with methadone, buprenorphine and naloxone. Similar to telaprevir, boceprevir led to a $15 \%$ decrease of R-methadone exposure. No free methadone concentrations were performed. Boceprevir was also associated with an increase of naloxone and buprenorphine exposure by $19 \%$ and $33 \%$, respectively, which is considered to be clinically nonsignificant (189).

\section{RECOMMENDATIONS}

37. Assessment and monitoring of drug-drug interactions between boceprevir and telaprevir and commonly prescribed medications should occur at baseline and at frequent intervals during $\mathrm{HCV}$ therapy (Class 1, Level C).

38. Ensuring that medication records are up to date, use of a systematic approach to identify combinations of potential concern, consulting pertinent $\mathrm{HIV}$ and/or HCV drug interaction resources (eg, www.hiv-druginteractions.org, www.hivclinic.ca, www.hepdruginteractions.org, www.hcvdruginfo.ca) and frequent patient monitoring are recommended to mitigate drug-drug interaction risk (Class 1, Level C).

39. Nonessential medications should be discontinued for the duration of HCV treatment, particularly when HCV PIs are used (Class 1, Level C). 


\section{ADVERSE EVENTS AND MANAGEMENT OF TREATMENT-RELATED CYTOPENIAS}

Both HIV antiretrovirals and current HCV antivirals have multiple side effects. For instance, pegylated interferon and ribavirin have side effects that overlap with those of efavirenz, potentially resulting in additive central nervous system effects including depression, mood changes and suicidality. A comprehensive review of HCV antiviral treatment side effects and management is beyond the scope of the present guideline statement but can be found elsewhere (190).

With boceprevir-containing triple therapy, the types of adverse events appear to be similar in frequency and severity to those reported in HCV monoinfected patients (128). Gastrointestinal adverse effects, including anorexia, diarrhea, vomiting and dysgeusia, were more frequent in boceprevir recipients (28\% to $34 \%$ ) versus $15 \%$ to $18 \%$ in those who received only pegylated interferon and ribavirin. Adverse events with HIV-HCV coinfected recipients of telaprevir-interferon-ribavirin therapy were similar in frequency and severity to HCV monoinfected study populations receiving telaprevircontaining therapy (131). No severe rashes occurred in either group. Mild and moderate severity rashes occurred in $34 \%$ and $23 \%$ of telaprevir and placebo recipients, respectively.

Cytopenias are of particular relevance in HIV-HCV coinfection. Interferon causes a decrease in the total lymphocyte count, which can affect CD4 $\mathrm{T}$ cell count interpretation. CD4 percentage, rather than the absolute number, may be a more appropriate measure of immunological efficacy during HCV antiviral treatment. Prophylaxis for Pneumocystis carinii pneumonia and other opportunistic infections is not routinely recommended in cases in which the absolute CD4 count falls below 200 cells/ $\mu \mathrm{L}$ or CD4 percentage declines below 20\% during therapy with pegylated interferon and ribavirin, although some practitioners may choose to do so.

Anemia is a common treatment-related adverse event and is a consequence of ribavirin-related hemolysis, and boceprevir, telaprevir and interferon bone marrow suppression. Anemia developed in 37\% of monoinfected treatment-naive individuals receiving telaprevir compared with $19 \%$ in pegylated interferon/ribavirin recipients (123), with $9 \%$ developing a hemoglobin level $<85 \mathrm{~g} / \mathrm{L}$ compared with $2 \%$ in the control arm. In boceprevir studies involving treatment-naive populations, anemia was observed in $49 \%$ of boceprevir subjects versus $29 \%$ of controls (121). Overall, $13 \%$ of controls and $21 \%$ of boceprevir recipients required ribavirin dose reductions because of anemia. Erythropoietin was administered in $24 \%$ of controls and $43 \%$ of boceprevir recipients (121).

Anemia rates in HIV-HCV coinfected patients appear to be similar to those observed in monoinfected individuals. In boceprevir-treated patients, rates of anemia were $41 \%$ compared with $26 \%$ in the control arm (128). Erythropoietin was used in $38 \%$ and $21 \%$ of study patients.

Development of anemia or ribavirin dose reduction in monoinfected individuals is not associated with decreased SVR in boceprevir- or telaprevir-treated patients. Furthermore, there was no difference in SVR between those in whom ribavirin dose reduction was used to manage anemia compared with patients managed with erythropoietin (191). Similar data are not available for HIV-HCV coinfected populations.

Neutropenia is related to interferon therapy, and increased rates of neutropenia were also observed in individuals receiving boceprevir (121). However, infection risk is not increased with HCV treatmentrelated neutropenia. In a retrospective analysis of 192 individuals who received HCV therapy between 2000 and 2005 (192), the infection rate was 1.17 per 100 person-weeks of therapy. In regression analysis, no association with degree of neutropenia was identified (192). Similar results have been observed in other cohorts $(193,194)$ and a randomized trial of dose reduction versus growth factor (granulocyte colony stimulating factor or erythropoietin) for HCV-related cytopenias in HIV-HCV coinfection (195). These results suggest use of aggressive dose reduction of interferon or use of granulocyte colony-stimulating factor are not warranted.
Cirrhotic HCV monoinfected patients treated with boceprevir and telaprevir through the compassionate access program in France (CUPIC ANRS C020) experienced increased risk of severe side effects, including anemia, with need for transfusions and use of erythropoietin. Overall, side effects were more severe in this cohort, and included sepsis, liver decompensation and several reported deaths (196). In CUPIC, the combination of baseline albumin level $<35 \mathrm{~g} / \mathrm{L}$ and platelets $<100 \times 10^{9} / \mathrm{L}$ identified patients at high risk for experiencing sepsis, liver decompensation or death.

\section{RECOMMENDATIONS}

40. Close monitoring for side effects during HCV therapy is required (Class 1, Level C).

41. Anemia related to HCV PIs should be primarily managed with ribavirin dose reduction. Erythropoietin use is not recommended for first-line management of anemia (Class 2b, Level B).

42. Neutropenia developing during HCV therapy is not associated with increased infection risk. Aggressive dose reduction of pegylated interferon and/or ribavirin, or granulocyte colony stimulating factor use is not recommended (Class 2b, Level C).

\section{HIV AND LIVER TRANSPLANTATION}

The management of ESLD includes orthotopic liver transplantation. HIV should not be a contraindication to transplant. Guidelines for liver transplant have been developed in both Europe and the United States (197-199). In addition to meeting requirements for liver transplantation, HIV-infected patients must demonstrate virological suppression and CD4 counts $>200$ cells $/ \mu \mathrm{L}$, and must have no recent history of opportunistic infections. Although outcomes of transplant among HIVinfected individuals have been evaluated in only small cohort studies, short-term outcomes appear to be similar to general transplant populations, while long-term survival may be reduced and infectious complications increased (200-202). A recent review (203) of the transplant program in Spain (84 coinfected patients) found a five-year survival rate of $54 \%$ compared with $71 \%$ for HCV monoinfected patients. Similarly, in a review of the German transplant experience (204), 60\% (19 of 32) of patients had a median survival of 60 months.

$\mathrm{HCV}$ recurrence is nearly universal after transplantation in both monoinfected and coinfected patients. Treatment of HCV posttransplant is complex. Consideration of use of current DAAs is, again, limited by drug-drug interactions. DAAs are known to interfere with CYP3A4 and P-glycoprotein, but the predicted interaction is not always as expected (205). Liver transplant patients on immunosuppressive drugs are at particular risk for serious drug interactions because cyclosporine and tacrolimus metabolism are highly dependent on CYP3A4 (206) Boceprevir and telaprevir interaction with cyclosporine in healthy volunteers led to an increase of cyclosporine exposure by 2.7 - and 4.6-fold, respectively $(207,208)$. The magnitude of the interaction was greater with tacrolimus, with an increase of 17- and 70-fold for boceprevir and telaprevir exposure, respectively. Clearly, there is a need for the development of a dosing protocol for immunosuppressive drugs. In the meantime, extreme caution is to be exercised. Until more information is available in HCV-infected individuals, the decision to coadminister current DAAs with cyclosporine or tacrolimus should be made on a case-bycase basis with the support of experts in pharmacology, hepatology and infectious diseases $(209,210)$. Fortunately, the investigational DAAs simeprevir and sofosbuvir, both of which have been submitted for regulatory review, have no significant drug interactions with tacrolimus or sirolimus.

\section{RECOMMENDATION}

43. HIV-HCV coinfected patients should be considered for liver transplantation, assuming all necessary criteria are met (Class 2a, Level C). 


\section{CONCLUSIONS}

HIV-HCV coinfection is common in Canada and is associated predominantly with history of receipt of $\mathrm{HCV}$-infected blood products before universal screening, or history of substance use; sexual transmission among HIV-infected MSM has also emerged as a risk for acquiring $\mathrm{HCV}$. Coinfected individuals have a heavy burden of concurrent comorbid conditions that affect health status and outcomes. As such, harm-reduction strategies should be implemented to decrease risk of infection among high-risk populations such as injection drug users and incarcerated individuals.

Coinfection is associated with increased risk of progression of liver disease. ESLD is a chief cause of morbidity and mortality among coinfected individuals.

All HIV-HCV coinfected individuals should be assessed for HCV therapy. Early initiation at CD4 cell counts $\geq 500$ cells $/ \mu \mathrm{L}$ may avoid drug-drug interactions, diminish pill burden issues due to concomitant HIV and HCV medication dosing, and improve future tolerability of antiretroviral agents. In individuals who are unable to initiate HCV therapy due to unstable comorbid conditions, consideration should be given to early ART initiation as a means to slow liver disease progression.

Current standard of care for genotype 1-infected patients consists of pegylated interferon, ribavirin and a HCV PI (boceprevir or telaprevir). Careful assessment of drug-drug interactions with ART and other common medications is necessary when using these agents. At present, a fixed-duration 48-week course of total therapy with pegylated interferon and ribavirin, with 12 weeks of telaprevir or 44 weeks of boceprevir, is recommended. Currently, there are no data to guide decisions regarding shortening treatment length or retreatment in coinfected individuals.

Current standard of care for genotype 2/3-infected patients remains dual therapy with pegylated interferon and ribavirin. Weight-based dosing of ribavirin is recommended. Response-guided therapy can be undertaken with 24 weeks of therapy if an RVR is achieved, and 48 weeks if a RVR is not attained or cirrhosis is present.

In individuals with mild liver disease, conservative monitoring with deferral of therapy pending access to novel DAA regimens with anticipated lower pill burden and fewer adverse events may be considered.

HIV should not be considered a barrier to liver transplant in coinfected patients.

\section{SUMMARY OF RECOMMENDATIONS}

\section{Epidemiology of HIV and hepatitis $\mathrm{C}$ virus coinfection}

1. All HIV-positive individuals should undergo screening for HCV antibodies when first evaluated. Screening should be repeated periodically - at least annually, particularly for highrisk individuals initially found to be negative (such as active injection drug users, Aboriginal peoples and individuals who are/have been incarcerated). HIV-positive MSM should undergo screening for HCV antibodies annually in combination with testing of liver enzyme levels every six months if sexually active with high-risk behaviours, and repeat HCV antibody testing (with consideration of additional HCV RNA testing) should be performed whenever unexplained elevations in liver enzyme levels are noted (Class 2a, Level C).

2. Identification of HCV coinfection in HIV provides opportunities for prevention of transmission, risk reduction, counselling, and linkage to care and harm-reduction services (Class 1, Level C)

3. Initiation of ART may serve to slow progression of liver disease in coinfected patients. Early initiation of ART is recommended for all individuals with CD4 count $<500$ cells $/ \mu \mathrm{L}$ (Class 1, Level B).

\section{Managing HIV in the setting of coinfection}

4. Initiation of ART in individuals with CD4 count $\geq 500 \mathrm{cell} / \mu \mathrm{L}$ can be considered if initiation of HCV therapy is not believed to be an option (Class 2a, Level B) in patients who have undergone thorough assessment of barriers to ART adherence and counselling regarding the long-term nature of ART.

5. Current first- and second-line ART regimens should be initiated as per current guidelines because they are effective and well-tolerated in coinfected patients (Class 1, Level A).

6. HCV therapy should be considered before ART initiation in individuals with early HIV disease as a potential means of decreasing risk of antiretroviral-related hepatotoxicity and to avoid risk of drug interactions between ART and HCV therapies (Class 2a, Level C).

\section{Baseline evaluation and management of $\mathrm{HCV}$ in coinfected patients}

7. Patients with confirmed HCV antibody should be evaluated using HCV RNA polymerase chain reaction (Class 1, Level C).

8. Individuals with positive HCV RNA tests should undergo HCV genotyping (Class 1, Level C).

9. Individuals with negative HCV RNA tests should undergo repeat testing at least once to confirm spontaneous clearance if liver enzyme levels are elevated (Class 1, Level C).

10. All patients should undergo screening for hepatitis A and B, and should be offered vaccination if nonimmune (Class 1 , Level C).

11. Patients should be evaluated for other conditions that may result in or aggravate chronic liver disease (Table 4) (Class 1, Level C).

12. All patients should be counselled regarding alcohol reduction/ abstinence (Class 1, Level C).

13. ALT criteria alone should not be used to determine the need for treatment initiation in coinfected patients (Class 2a, Level C).

14. Baseline abdominal ultrasound should be considered in all patients (Class 2a, Level B).

15. Baseline evaluation of liver fibrosis (eg, Fibroscan, Fibrotest, APRI) to determine the degree of hepatic fibrosis and urgency for HCV therapy is advised (Class 2a, Level B).

16. Evaluation of liver fibrosis with liver biopsy can be considered if noninvasive methods of determining fibrosis are not available or if alternative diagnoses are being considered.

17. Patients with evidence of underlying cirrhosis should be screened every six months for HCC using ultrasound (Class 1, Level B).

18. Patients with underlying cirrhosis should be considered for gastroscopy to screen for esophageal varices (Class 1, Level B).

\section{HCV therapy in coinfected patients}

19. All coinfected patients should undergo evaluation for $\mathrm{HCV}$ therapy (Class 1, Level A).

20. Evaluation of factors such as substance use/addictions, mental health, and housing and food security is vital when preparing for HCV therapy (Class 1, Level B).

21. Addiction should not be considered to be an absolute exclusion criteria for HCV therapy.

22. Multidisciplinary care is recommended to optimally support patients as they progress through HCV work-up and treatment (Class 1, Level B).

23. A detailed assessment for interferon-based treatment contraindications is essential (Class 1, Level C).

24. Appropriate levels of funding for HCV treatment programs and removal of barriers to HCV antiviral therapy are necessary to optimize engagement in care and treatment outcomes (Class 1, Level C).

25. Genotype 1-infected HIV-HCV coinfected patients should be treated with either boceprevir or telaprevir in combination with pegylated interferon and ribavirin (Class 1, Level A). 
26. Telaprevir should be used for the first 12 weeks, while boceprevir should begin after a four-week lead-in of pegylated interferon and ribavirin and continue for the remainder of therapy (Class 1, Level A).

27. At this time, a full 48-week course of pegylated interferon and ribavirin is recommended because there is no current evidence regarding response-guided therapy in coinfected patients (Class 1, Level C).

28. Standard stopping rules at weeks 4,12 and 24 (telaprevir), or 8, 12 and 24 (boceprevir) developed for monoinfection should be applied to the HIV-HCV coinfection context (Class 1, Level C).

29. No published SVR data currently exist for retreatment of genotype 1 null responders, partial responders or previous relapsers in the setting of HIV coinfection. However, retreatment following protocols developed for monoinfected patients can be considered (Class 2b, Level C).

30. For genotypes 2 and 3, weight-based ribavirin dosing, a 24-week treatment duration in those who achieve RVR, and a 48-week treatment duration in those without RVR or in those with significant fibrosis is recommended (Class 1, Level A).

31. Careful attention to drug-drug interactions between HCV antivirals and concurrently administered HIV and non-HIV medications is critical to avoid viral breakthrough of either HIV or HCV, development of resistance, suboptimal disease/ symptom management and drug toxicities (Class 1, Level C).

32. Use of zidovudine, stavudine and didanosine regimens should be avoided in coinfected patients being considered for HCV therapy (Class 1, Level C).

33. For individuals with genotype 1 infection initiating HCV therapy, use of raltegravir-based regimens (boceprevir and telaprevir) or atazanavir/ritonavir (telaprevir) are first-line antiretroviral options (Class 2b, Level B). Rilpivirine-based therapy may be an acceptable first-line regimen (telaprevir, boceprevir).

34. For individuals with genotype 1 infection initiating $\mathrm{HCV}$ therapy, use of efavirenz (telaprevir with dose adjustment), or etravirine (acceptable with telaprevir but clinical implications of a potential interaction with boceprevir remain uncertain) and maraviroc (telaprevir, boceprevir) may be considered (Class 2b, Level B)

35. For individuals with genotype 1 infection initiating $\mathrm{HCV}$ therapy, switching from alternative regimens to an acceptable regimen as listed above can be considered if HIV treatment history and resistance profile permits such a switch.

36. For patients with HIV multidrug resistance who are well controlled on nonpreferred ART regimens, initiation of triple therapy, including DAAs, may be considered in consultation with an expert physician and pharmacist with experience in managing HIV and HCV drug interactions.

37. Assessment and monitoring of drug-drug interactions between boceprevir and telaprevir and commonly prescribed medications should occur at baseline and at frequent intervals during HCV therapy (Class 1, Level C).

38. Ensuring that medication records are up to date, use of a systematic approach to identify combinations of potential concern, consulting pertinent HIV and/or HCV drug interaction resources (eg, www.hiv-druginteractions.org, www.hivclinic.ca, www.hep-druginteractions.org, www.hcvdruginfo.ca) and frequent patient monitoring are recommended to mitigate drugdrug interaction risk (Class 1, Level C).

39. Nonessential medications should be discontinued for the duration of HCV treatment, particularly when HCV PIs are used (Class 1, Level C).

V. Adverse events and management of treatment-related cytopenias

40. Close monitoring for side effects during HCV therapy is required (Class 1 , Level C).
41. Anemia related to HCV PIs should be primarily managed with ribavirin dose reduction. Erythropoietin use is not recommended for first-line anemia management (Class 2b, Level B).

42. Neutropenia developing during HCV therapy is not associated with increased infection risk. Aggressive dose reduction of pegylated interferon and/or ribavirin, or granulocyte colony-stimulating factor use is not recommended (Class 2b, Level C).

\section{HIV and liver transplantation}

43. HIV-HCV coinfected patients should be considered for liver transplantation assuming all necessary criteria are met (Class 2a, Level C).

\section{APPENDIX}

The CIHR Canadian HIV Trials Network HIV-HCV Coinfection Guideline Working Group includes:

- Brian Conway - Vancouver Infectious Diseases Centre, Vancouver, British Columbia;

- Curtis Cooper - University of Ottawa, Ottawa Hospital Research Institute, Ottawa, Ontario;

- Pierre Côté - Clinique médicale du Quartier Latin, Montréal, Québec;

- Pierre Giguère - The Ottawa Hospital, Ottawa, Ontario;

- Mark Hull - University of British Columbia/BC Centre for Excellence in HIV/AIDS, Vancouver, British Columbia;

- Marina Klein - Institut thoracique de Montréal, Montréal, Québec;

- Marc Poliquin - Clinique médicale du Quartier Latin, Montréal, Québec;

- Stephen Shafran - University of Alberta, Edmonton, Alberta;

- Alice Tseng - Toronto General Hospital, Toronto, Ontario;

- Marie-Louise Vachon - Centre Hospitalier Universitaire de Québec, Québec, Québec;

- Sylvie Vézina - Clinique médicale l'Actuel, Montréal, Québec;

- Sharon Walmsley - University of Toronto, Toronto, Ontario.

FUNDING: Support for the development of these guidelines was provided from The Canadian Institutes for Health Research Canadian HIV Trials Network, CIHR Dissemination Grant Program and the Canadian Association for HIV Research. Unrestricted funding from Merck Canada, Abbvie, Vertex, Janssen, Roche and Gilead Sciences is gratefully acknowledged.

DISCLOSURES: MH has consulted and spoken for Bristol Myers Squibb, Gilead, Merck, Janssen and Vertex. MK has served as a consultant for GlaxoSmithKline and Viiv Healthcare, holds grants from Merck, has spoken for Bristol Myers Squibb, GlaxoSmithKline and Viiv Healthcare and has developed educational presentations from Gilead, GlaxoSmithKline and Viiv Healthcare. SS and CC have consulted and spoken for AbbVie, Boehringer Ingelheim, Bristol Myers Squibb, Gilead, Janssen, Merck, Roche and Vertex. PC has consulted for Gilead and Vertex and obtained research funding from Janssen, BMS, Abbvie and Gilead. AT has received unrestricted educational grants and/or spoken for Merck, Gilead and Vertex. PG received educational grants from Merck and Vertex.

ACKNOWLEDGEMENTS: The authors thank Andrew Matejcic from the Canadian Association for HIV Research and Kevin Pendergraft from CIHR CTN for their contributions to guideline development and knowledge translation.

\section{REFERENCES}

1. Nakagawa F, Lodwick RK, Smith CJ, et al. Projected life expectancy of people with HIV according to timing of diagnosis. AIDS (London, England) 2012;26:335-43.

2. Ly KN, Xing J, Klevens RM, Jiles RB, Ward JW, Holmberg SD. The increasing burden of mortality from viral hepatitis in the United States between 1999 and 2007. Ann Intern Med 2012;156:271-8. 
3. Weber R, Sabin CA, Friis-Moller N, et al. Liver-related deaths in persons infected with the human immunodeficiency virus: The D:A:D study. Arch Intern Med 2006;166:1632-41.

4. Coffin CS, Fung SK, Ma MM, Canadian Association for the Study of the Liver. Management of chronic hepatitis B: Canadian Association for the Study of the Liver consensus guidelines. Can J Gastroenterol 2012;26:917-38.

5. Myers RP, Ramji A, Bilodeau M, Wong S, Feld JJ. An update on the management of hepatitis $\mathrm{C}$ : Consensus guidelines from the Canadian Association for the Study of the Liver. Can J Gastroenterol 2012;26:359-75.

6. Lima VD, Hogg RS, Harrigan PR, et al. Continued improvement in survival among HIV-infected individuals with newer forms of highly active antiretroviral therapy. AIDS (London, England) 2007;21:685-92.

7. Hogg RS, Yip B, Kully C, et al. Improved survival among HIVinfected patients after initiation of triple-drug antiretroviral regimens. CMAJ 1999;160:659-65.

8. Thomas DL. The challenge of hepatitis $\mathrm{C}$ in the HIV-infected person. Ann Rev Med 2008;59:473-85.

9. Klein MB, Rollet K, Saeed S, et al. HIV and hepatitis C virus co-infection in Canada: Challenges and opportunities for reducing preventable morbidity and mortality. HIV Med 2013;14:10-20.

10. Shepard CW, Finelli L, Alter MJ. Global epidemiology of hepatitis C virus infection. Lancet Infect Dis 2005;5:558-67.

11. Hepatitis $\mathrm{C}$ - global prevalence (update): World Health Organization, 2003. <www.who.int/csr/disease/hepatitis/Hepc.pdf> (Accessed October 16, 2013).

12. Epidemiology of Acute Hepatitis C Infection in Canada: Results from the Enhanced Hepatitis Strain Surveillance System (EHSSS). Public Health Agency of Canada, 2008. <www.phac-aspc.gc.ca/stiits-surv-epi/pdf/hcv-epi-eng.pdf> (Accessed May 17, 2013).

13. Remis RS. Modelling the incidence and prevalence of hepatitis $C$ infection and its sequelae in Canada, 2007. In: Community Acquired Infections Division CDa IPB. Ottawa: Public Health Agency of Canada, 2007.

14. Althoff KN, Eichelberger M, Gange SJ, et al. Seroincidence of 2009 H1N1 infection in HIV-infected and HIV-uninfected women prior to vaccine availability. AIDS (London, England) 2011;25:1229-32.

15. Parent R, Alary M, Morissette C, Roy E, Leclerc P, Allard PR. Surveillance des maladies infectieuses chez les utilisateurs de drogue par injection: épidémiologie du VIH de 1995 à 2008: Institut National de Santé Publique. 2009. <www.inspq.qc.ca/pdf/ publications/1021_SurvMalInfecUDI_VIHVHC2008.pdf> (Accessed October 16, 2013).

16. Public Health Agency of Canada. HIV/AIDS Among Aboriginal People in Canada. HIV/AIDS Epi Updates, July 2010. Ottawa: Surveillance and Risk Assessment Division, Centre for Communicable Diseases and Infection Control, 2010.

17. Saskatchewan Ministry of Health. Saskatchewan HIV Strategy. 2012 <www.health.gov.sk.ca/HIV-strategy-update> (Accessed April 2013).

18. Wood E, Montaner JS, Li K, et al. Burden of HIV infection among Aboriginal injection drug users in Vancouver, British Columbia. Am J Public Health 2008;98:515-9.

19. Calzavara L, Ramuscak N, Burchell AN, et al. Prevalence of HIV and hepatitis $C$ virus infections among inmates of Ontario remand facilities. CMAJ 2007;177:257-61.

20. Zakaria D, Thompson JM, Jarvis A, Borgatta F. Summary of emerging findings from the 2007 National Inmate Infectious Diseases and Risk-Behaviours Survey. Correctional Service Canada, 2010.

21. Miller CL, Johnston C, Spittal PM, et al. Opportunities for prevention: Hepatitis $C$ prevalence and incidence in a cohort of young injection drug users. Hepatology 2002;36:737-42.

22. Spittal PM, Pearce ME, Chavoshi N, et al. The Cedar Project: High incidence of HCV infections in a longitudinal study of young Aboriginal people who use drugs in two Canadian cities. BMC Publ Health 2012;12:632.

23. Collins CL, Kerr T, Tyndall MW, et al. Rationale to evaluate medically supervised safer smoking facilities for non-injection illicit drug users. Can J Public Health 2005;96:344-47.

24. Wood E, Kerr T, Spittal PM, et al. The potential public health and community impacts of safer injecting facilities: Evidence from a cohort of injection drug users. J Acquir Immune Defic Syndr $1999 ; 2003 ; 32: 2-8$.
25. Wood E, Kerr T, Montaner JS, et al. Rationale for evaluating North America's first medically supervised safer-injecting facility. Lancet Infect Dis 2004:4:301-6.

26. Kerr T, Stoltz JA, Tyndall M, et al. Impact of a medically supervised safer injection facility on community drug use patterns: A before and after study. BMJ 2006;332:220-2.

27. Clarke JG, Stein MD, Hanna L, Sobota M, Rich JD. Active and former injection drug users report of HIV risk behaviors during periods of incarceration. Subst Abus 2001;22:209-16.

28. Milloy MJ, Wood E, Small W, et al. Incarceration experiences in a cohort of active injection drug users. Drug Alcohol Rev 2008;27:693-9.

29. Orsi MM, Brochu S. [The place of syringe exchange programs in reducing harm in Canadian prisoners]. Can J Public Health 2009;100:29-31.

30. Buxton JA, Yu A, Kim PH, et al. HCV co-infection in HIV positive population in British Columbia, Canada. BMC Publ Health 2010;10:225.

31. Terrault NA, Dodge JL, Murphy EL, et al. Sexual transmission of hepatitis $\mathrm{C}$ virus among monogamous heterosexual couples: The HCV partners study. Hepatology 2013;57:881-9.

32. Urbanus AT, van de Laar TJ, Stolte IG, et al. Hepatitis C virus infections among HIV-infected men who have sex with men: An expanding epidemic. AIDS 2009;23:F1-7.

33. Danta M, Dusheiko GM. Acute HCV in HIV-positive individuals a review. Curr Pharm Des 2008;14:1690-7.

34. Vogel M, Rockstroh JK. Treatment of acute hepatitis C in HIV infection. J Antimicrob Chemother 2010;65:4-9.

35. Wright TL, Hollander H, Pu X, et al. Hepatitis C in HIV-infected patients with and without AIDS: Prevalence and relationship to patient survival. Hepatology 1994;20:1152-5.

36. Yaphe S, Bozinoff N, Kyle R, Shivkumar S, Pai NP, Klein M. Incidence of acute hepatitis $\mathrm{C}$ virus infection among men who have sex with men with and without HIV infection: A systematic review. Sex Transm Infect 2012;88:558-64.

37. Richardson D, Fisher M, Sabin CA. Sexual transmission of hepatitis C in MSM may not be confined to those with HIV infection. J Infect Dis 2008;197:1213-4.

38. van de Laar T, van der Bij A, Prins M, et al. Increase in HCV incidence among men who have sex with men in Amsterdam most likely caused by sexual transmission. J Infect Dis 2007;196:230-8.

39. Jin F, Prestage GP, Matthews G, et al. Prevalence, incidence and risk factors for hepatitis $\mathrm{C}$ in homosexual men: Data from two cohorts of HIV-negative and HIV-positive men in Sydney, Australia. Sex Transm Infect 2010;86:25-8.

40. Matthews GV, Pham ST, Hellard M, et al. Patterns and characteristics of hepatitis $\mathrm{C}$ transmission clusters among HIVpositive and HIV-negative individuals in the Australian trial in acute hepatitis C. Clin Infect Dis 2011;52:803-11.

41. Acute hepatitis $\mathrm{C}$ in HIV-infected individuals: Recommendations from the European AIDS Treatment Network (NEAT) consensus conference. AIDS 2011;25:399-409.

42. Linas BP, Wong AY, Schackman BR, Kim AY, Freedberg KA. Cost-effective screening for acute hepatitis $\mathrm{C}$ virus infection in HIV-infected men who have sex with men. Clin Infect Dis 2012;55:279-90.

43. Klein MB, Saeed S, Yang H, et al. Cohort profile: The Canadian HIV-Hepatitis C Co-infection Cohort Study. Int J Epidemiol 2010;39:1162-9.

44. Andonov A, Chaudhary RK. Genotyping of Canadian hepatitis C virus isolates by PCR. J Clin Microbiol 1994;32:2031-4.

45. de Bruijne J, Schinkel J, Prins M, et al. Emergence of hepatitis C virus genotype 4: Phylogenetic analysis reveals three distinct epidemiological profiles. J Clin Microbiol 2009;47:3832-8.

46. Armstrong GL, Alter MJ, McQuillan GM, Margolis HS. The past incidence of hepatitis $\mathrm{C}$ virus infection: Implications for the future burden of chronic liver disease in the United States. Hepatology 2000;31:777-82.

47. Graham CS, Baden LR, Yu E, et al. Influence of human immunodeficiency virus infection on the course of hepatitis $C$ virus infection: A meta-analysis. Clin Infect Dis 2001;33:562-9.

48. Sanchez-Quijano A, Andreu J, Gavilan F, et al. Influence of human immunodeficiency virus type 1 infection on the natural course of chronic parenterally acquired hepatitis C. Eur J Clin Microbiol Infect Dis 1995;14:949-53.

49. Soto B, Sanchez-Quijano A, Rodrigo L, et al. Human immunodeficiency virus infection modifies the natural history of 
chronic parenterally-acquired hepatitis $\mathrm{C}$ with an unusually rapid progression to cirrhosis. J Hepatol 1997;26:1-5.

50. Thein HH, Yi Q, Dore GJ, Krahn MD. Natural history of hepatitis C virus infection in HIV-infected individuals and the impact of HIV in the era of highly active antiretroviral therapy: A meta-analysis. AIDS 2008;22:1979-91.

51. Fierer DS, Uriel AJ, Carriero DC, et al. Liver fibrosis during an outbreak of acute hepatitis C virus infection in HIV-infected men: A prospective cohort study. J Infect Dis 2008;198:683-6.

52. Rosenthal E, Salmon-Ceron D, Lewden C, et al. Liver-related deaths in HIV-infected patients between 1995 and 2005 in the French GERMIVIC Joint Study Group Network (Mortavic 2005 study in collaboration with the Mortalite 2005 survey, ANRS EN19). HIV Med 2009;10:282-9.

53. Salmon-Ceron D, Rosenthal E, Lewden C, et al. Emerging role of hepatocellular carcinoma among liver-related causes of deaths in HIV-infected patients: The French national Mortalite 2005 study. J Hepatol 2009;50:736-45.

54. Giordano TP, Kramer JR, Souchek J, Richardson P, El-Serag HB. Cirrhosis and hepatocellular carcinoma in HIV-infected veterans with and without the hepatitis C virus: A cohort study, 1992-2001. Arch Intern Med 2004;164:2349-54.

55. Kramer JR, Giordano TP, Souchek J, Richardson P, Hwang LY, El-Serag HB. The effect of HIV coinfection on the risk of cirrhosis and hepatocellular carcinoma in U.S. veterans with hepatitis C. Am J Gastroenterol 2005;100:56-63.

56. Merchante N, Merino E, Lopez-Aldeguer J, et al. Increasing incidence of hepatocellular carcinoma in HIV-infected patients in Spain. Clin Infect Dis 2013;56:143-50.

57. Brau N, Fox RK, Xiao P, et al. Presentation and outcome of hepatocellular carcinoma in HIV-infected patients: A U.S.-Canadian multicenter study. J Hepatol 2007;47:527-37.

58. Garcia-Samaniego J, Rodriguez M, Berenguer J, et al. Hepatocellular carcinoma in HIV-infected patients with chronic hepatitis C. Am J Gastroenterol 2001;96:179-83.

59. Kwong JC, Crowcroft NS, Campitelli MA, et al. Ontario Burden of Infectious Disease Study (ONBOIDS): An OAHPP/ICES Report. Toronto: Ontario Agency for Health Protection and Promotion, Institute for Clinical Evaluative Sciences, 2010.

60. Werb D, Wood E, Kerr T, Hershfield N, Palmer RW, Remis RS. Treatment costs of hepatitis $\mathrm{C}$ infection among injection drug users in Canada, 2006-2026. Int J Drug Policy 2011;22:70-6.

61. Brau N, Salvatore M, Rios-Bedoya CF, et al. Slower fibrosis progression in HIV/HCV-coinfected patients with successful HIV suppression using antiretroviral therapy. J Hepatol 2006;44:47-55.

62. Tural C, Fuster D, Tor J, et al. Time on antiretroviral therapy is a protective factor for liver fibrosis in HIV and hepatitis $\mathrm{C}$ virus (HCV) co-infected patients. J Viral Hepatitis 2003;10:118-25.

63. Qurishi N, Kreuzberg C, Luchters G, et al. Effect of antiretroviral therapy on liver-related mortality in patients with HIV and hepatitis C virus coinfection. Lancet 2003;362:1708-13.

64. Bonacini M, Louie S, Bzowej N, Wohl AR. Survival in patients with HIV infection and viral hepatitis B or C: A cohort study. AIDS 2004;18:2039-45.

65. Shafran SD. Early initiation of antiretroviral therapy: The current best way to reduce liver-related deaths in HIV/hepatitis $\mathrm{C}$ viruscoinfected patients. J Acquir Immune Defic Syndr 2007;44:551-6.

66. Thompson MA, Aberg JA, Hoy JF, et al. Antiretroviral treatment of adult HIV infection: 2012 recommendations of the International Antiviral Society-USA panel. JAMA 2012;308:387-402.

67. Panel on Antiretroviral Guidelines for Adults and Adolescents. Guidelines for the use of antiretroviral agents in HIV-1-infected adults and adolescents. Department of Health and Human Services. February 12, 2013; 1-267. <www.aidsinfo.nih.gov/ContentFiles/ AdultandAdolescentGL.pdf> (Accessed February 27, 2013).

68. Williams I, Churchill D, Anderson J, et al. British HIV Association guidelines for the treatment of HIV-1-positive adults with antiretroviral therapy 2012. HIV Med 2012;(13 Suppl 2):1-85.

69. Clumeck N, d'Arminio Monforte A, Arribas JR, et al. European AIDS Clinical Society. Guidelines: Clinical Management and Treatment of HIV-infected adults in Europe. Version 6.1 - November 2012. <www. sm.ee/fileadmin/meedia/Dokumendid/Tervisevaldkond/Tervishoid/ EACSGuidelines_v6.1_Nov2012.pdf> (Accessed January 5, 2013).

70. Labarga P, Soriano V, Vispo ME, et al. Hepatotoxicity of antiretroviral drugs is reduced after successful treatment of chronic hepatitis C in HIV-infected patients. J Infect Dis 2007;196:670-6.
71. Macias J, Castellano V, Merchante N, et al. Effect of antiretroviral drugs on liver fibrosis in HIV-infected patients with chronic hepatitis C: Harmful impact of nevirapine. AIDS 2004;18:767-74.

72. Moodie EE, Pant Pai N, Klein MB. Is antiretroviral therapy causing long-term liver damage? A comparative analysis of HIV-mono-infected and HIV/hepatitis $\mathrm{C}$ co-infected cohorts. PLoS One 2009;4:e4517.

73. Sulkowski MS, Thomas DL, Chaisson RE, Moore RD. Hepatotoxicity associated with antiretroviral therapy in adults infected with human immunodeficiency virus and the role of hepatitis C or B virus infection. JAMA 2000;283:74-80.

74. Nunez M. Hepatotoxicity of antiretrovirals: Incidence, mechanisms and management. J Hepatol 2006;44(1 Suppl):S132-39.

75. Nunez M, Lana R, Mendoza JL, Martin-Carbonero L, Soriano V. Risk factors for severe hepatic injury after introduction of highly active antiretroviral therapy. J Acquir Immune Defic Syndr 2001;27:426-31.

76. Wit FW, Weverling GJ, Weel J, Jurriaans S, Lange JM. Incidence of and risk factors for severe hepatotoxicity associated with antiretroviral combination therapy. J Infect Dis 2002;186:23-31.

77. Servoss JC, Kitch DW, Andersen JW, Reisler RB, Chung RT, Robbins GK. Predictors of antiretroviral-related hepatotoxicity in the adult AIDS Clinical Trial Group (1989-1999). J Acquir Immune Defic Syndr 2006;43:320-3.

78. Aceti A, Pasquazzi C, Zechini B, De Bac C. Hepatotoxicity development during antiretroviral therapy containing protease inhibitors in patients with HIV: The role of hepatitis B and C virus infection. J Acquir Immune Defic Syndr 2002;29:41-8.

79. den Brinker M, Wit FW, Wertheim-van Dillen PM, et al. Hepatitis B and $\mathrm{C}$ virus co-infection and the risk for hepatotoxicity of highly active antiretroviral therapy in HIV-1 infection. AIDS 2000;14:2895-902.

80. Sulkowski MS, Thomas DL, Mehta SH, Chaisson RE, Moore RD. Hepatotoxicity associated with nevirapine or efavirenz-containing antiretroviral therapy: Role of hepatitis C and B infections. Hepatology 2002;35:182-9.

81. Rockstroh J, Teppler H, Zhao J, et al. Safety and efficacy of raltegravir in patients with HIV-1 and hepatitis $B$ and/or $C$ virus coinfection. HIV Med 2012;13:127-31.

82. Nelson M, Amaya G, Clumeck N, et al. Efficacy and safety of rilpivirine in treatment-naive, HIV-1-infected patients with hepatitis $B$ virus/hepatitis $C$ virus coinfection enrolled in the phase III randomized, double-blind ECHO and THRIVE trials. J Antimicrob Chemother 2012;67:2020-8.

83. Clotet B, Clumeck N, Katlama C, Nijs S, Witek J. Safety of etravirine in HIV-1/hepatitis B and/or C virus co-infected patients: Pooled 96 week results from the phase III DUET trials. J Antimicrob Chemother 2010;65:2450-4.

84. Rachlis A, Clotet B, Baxter J, Murphy R, Lefebvre E. Safety, tolerability, and efficacy of darunavir (TMC114) with low-dose ritonavir in treatment-experienced, hepatitis B or C co-infected patients in POWER 1 and 3. HIV Clin Trials 2007;8:213-20.

85. Sax PE, DeJesus E, Mills A, et al. Co-formulated elvitegravir, cobicistat, emtricitabine, and tenofovir versus co-formulated efavirenz, emtricitabine, and tenofovir for initial treatment of HIV-1 infection: A randomised, double-blind, phase 3 trial, analysis of results after 48 weeks. Lancet 2012;379:2439-48.

86. DeJesus E, Rockstroh JK, Henry K, et al. Co-formulated elvitegravir, cobicistat, emtricitabine, and tenofovir disoproxil fumarate versus ritonavir-boosted atazanavir plus co-formulated emtricitabine and tenofovir disoproxil fumarate for initial treatment of HIV-1 infection: A randomised, double-blind, phase 3, non-inferiority trial. Lancet 2012;379:2429-38.

87. Aranzabal L, Casado JL, Moya J, et al. Influence of liver fibrosis on highly active antiretroviral therapy-associated hepatotoxicity in patients with HIV and hepatitis C virus coinfection. Clin Infect Dis 2005;40:588-93.

88. Nunez M, Rios P, Martin-Carbonero L, Perez-Olmeda M, Gonzalez-Lahoz J, Soriano V. Role of hepatitis C virus genotype in the development of severe transaminase elevation after the introduction of antiretroviral therapy. J Acquir Immune Defic Syndr 2002;30:65-8.

89. Torti C, Lapadula G, Puoti M, et al. Influence of genotype 3 hepatitis $\mathrm{C}$ coinfection on liver enzyme elevation in HIV-1-positive patients after commencement of a new highly active antiretroviral regimen: Results from the EPOKA-MASTER Cohort. J Acquir Immune Defic Syndr 2006;41:180-5. 
90. Beld M, Penning M, van Putten M, et al. Low levels of hepatitis C virus RNA in serum, plasma, and peripheral blood mononuclear cells of injecting drug users during long antibody-undetectable periods before seroconversion. Blood 1999;94:1183-91.

91. Soriano V, Mocroft A, Rockstroh J, et al. Spontaneous viral clearance, viral load, and genotype distribution of hepatitis $\mathrm{C}$ virus (HCV) in HIV-infected patients with anti-HCV antibodies in Europe. J Infect Dis 2008;198:1337-44.

92. Hull MW, Rollet K, Odueyungbo A, et al. Factors associated with discordance between absolute CD4 cell count and CD4 cell percentage in patients coinfected with HIV and hepatitis $\mathrm{C}$ virus. Clin Infect Dis 2012;54:1798-805.

93. Claassen CW, Diener-West M, Mehta SH, Thomas DL, Kirk GD. Discordance between CD4+ T-lymphocyte counts and percentages in HIV-infected persons with liver fibrosis. Clin Infect Dis 2012;54:1806-13.

94. Uberti-Foppa C, De Bona A, Galli L, et al. Liver fibrosis in HIVpositive patients with hepatitis $\mathrm{C}$ virus: Role of persistently normal alanine aminotransferase levels. J Acquir Immune Defic Syndr 2006;41:63-7.

95. Kleiner DE. The liver biopsy in chronic hepatitis C: A view from the other side of the microscope. Semin Liver Dis 2005;25:52-64

96. Regev A, Berho M, Jeffers LJ, et al. Sampling error and intraobserver variation in liver biopsy in patients with chronic HCV infection. Am J Gastroenterol 2002;97:2614-8.

97. Wong JB, Koff RS. Watchful waiting with periodic liver biopsy versus immediate empirical therapy for histologically mild chronic hepatitis C. A cost-effectiveness analysis. Ann Intern Med 2000;133:665-75.

98. de Ledinghen V, Vergniol J. Transient elastography for the diagnosis of liver fibrosis. Expert Rev Med Devices 2010;7:811-23.

99. Ziol M, Handra-Luca A, Kettaneh A, et al. Noninvasive assessment of liver fibrosis by measurement of stiffness in patients with chronic hepatitis C. Hepatology 2005;41:48-54.

100. Friedrich-Rust M, Ong MF, Martens S, et al. Performance of transient elastography for the staging of liver fibrosis: A meta-analysis. Gastroenterology 2008;134:960-74.

101. Stebbing J, Farouk L, Panos G, et al. A meta-analysis of transient elastography for the detection of hepatic fibrosis. J Clin Gastroenterol 2010;44:214-9.

102. Vergara S, Macias J, Rivero A, et al. The use of transient elastometry for assessing liver fibrosis in patients with HIV and hepatitis C virus coinfection. Clin Infect Dis 2007;45:969-74.

103. Kirk GD, Astemborski J, Mehta SH, et al. Assessment of liver fibrosis by transient elastography in persons with hepatitis $\mathrm{C}$ virus infection or HIV-hepatitis C virus coinfection. Clin Infect Dis 2009;48:963-72.

104. de Ledinghen V, Vergniol J, Foucher J, El-Hajbi F, Merrouche W, Rigalleau V. Feasibility of liver transient elastography with FibroScan using a new probe for obese patients. Liver Int 2010;30:1043-8.

105. Al-Mohri H, Cooper C, Murphy T, Klein MB. Validation of a simple model for predicting liver fibrosis in HIV/hepatitis $\mathrm{C}$ viruscoinfected patients. HIV Med 2005;6:375-8.

106. Al-Mohri H, Murphy T, Lu Y, Lalonde RG, Klein MB. Evaluating liver fibrosis progression and the impact of antiretroviral therapy in HIV and hepatitis $\mathrm{C}$ coinfection using a noninvasive marker. J Acquir Immune Defic Syndr 2007;44:463-9.

107. Sterling RK, Lissen E, Clumeck N, et al. Development of a simple noninvasive index to predict significant fibrosis in patients with HIV/HCV coinfection. Hepatology 2006;43:1317-25.

108. Poynard T, Morra R, Halfon P, et al. Meta-analyses of FibroTest diagnostic value in chronic liver disease. BMC Gastroenterol 2007;7:40.

109. Shaheen AA, Myers RP. Systematic review and meta-analysis of the diagnostic accuracy of fibrosis marker panels in patients with HIV/ hepatitis C coinfection. HIV Clin Trials 2008;9:43-51.

110. de Ledinghen V, Douvin C, Kettaneh A, et al. Diagnosis of hepatic fibrosis and cirrhosis by transient elastography in HIV/hepatitis C viruscoinfected patients. J Acquir Immune Defic Syndr 2006;41:175-9.

111. Sanchez-Conde M, Montes-Ramirez ML, Miralles P, et al Comparison of transient elastography and liver biopsy for the assessment of liver fibrosis in HIV/hepatitis $\mathrm{C}$ virus-coinfected patients and correlation with noninvasive serum markers. J Viral Hepat 2010;17:280-6.

112. Thomas DL, Thio CL, Martin MP, et al. Genetic variation in IL28B and spontaneous clearance of hepatitis C virus. Nature 2009;461:798-801.

113. Ge D, Fellay J, Thompson AJ, et al. Genetic variation in IL28B predicts hepatitis $\mathrm{C}$ treatment-induced viral clearance. Nature 2009;461:399-401.
114. Berenguer J, Alvarez-Pellicer J, Martin PM, et al. Sustained virological response to interferon plus ribavirin reduces liver-related complications and mortality in patients coinfected with human immunodeficiency virus and hepatitis $C$ virus. Hepatology 2009;50:407-13.

115. Grebely J, Raffa JD, Lai C, et al. Low uptake of treatment for hepatitis $\mathrm{C}$ virus infection in a large community-based study of inner city residents. J Viral Hepat 2009;16:352-8.

116. Vellozzi C, Buchacz K, Baker R, et al. Treatment of hepatitis $C$ virus (HCV) infection in patients coinfected with HIV in the HIV Outpatient Study (HOPS), 1999-2007. J Viral Hepat 2011;18:316-24.

117. Shahidullah AB, Cerulli MA, Berman DH. Interferon may cause retinopathy during hepatitis therapy. Am J Gastroenterol 1995;90:1543.

118. Okuse C, Yotsuyanagi H, Nagase Y, et al. Risk factors for retinopathy associated with interferon alpha- $2 \mathrm{~b}$ and ribavirin combination therapy in patients with chronic hepatitis C. World J Gastroenterol 2006;12:3756-9.

119. Grebely J, Conway B, Raffa JD, Lai C, Krajden M, Tyndall MW. Hepatitis $C$ virus reinfection in injection drug users. Hepatology 2006;44:1139-45.

120. Martin NK, Vickerman P, Foster GR, Hutchinson SJ, Goldberg DJ, Hickman M. Can antiviral therapy for hepatitis $\mathrm{C}$ reduce the prevalence of $\mathrm{HCV}$ among injecting drug user populations? A modeling analysis of its prevention utility. J Hepatol 2011;54:1137-44.

121. Poordad F, McCone J Jr, Bacon BR, et al. Boceprevir for untreated chronic HCV genotype 1 infection. N Engl J Med 2011;364:1195-206.

122. Bacon BR, Gordon SC, Lawitz E, et al. Boceprevir for previously treated chronic HCV genotype 1 infection. N Engl J Med 2011;364:1207-17.

123. Jacobson IM, McHutchison JG, Dusheiko G, et al. Telaprevir for previously untreated chronic hepatitis $\mathrm{C}$ virus infection. N Engl J Med 2011;364:2405-16.

124. Zeuzem S, Andreone P, Pol S, et al. Telaprevir for retreatment of HCV infection. N Engl J Med 2011;364:2417-28.

125. Buti M, Agarwal K, Horsmans Y, et al. Noninferiority of twice-daily telaprevir versus administration every 8 hours in treatment-naive, genotype $1 \mathrm{HCV}$-infected patients. The Liver Meeting 2012: American Association for the Study of Liver Diseases (AASLD) 63rd Annual Meeting. Boston, November 9 to 13, 2012.

126. Merck Canada Inc. Victrelis (boceprevir) Product Monograph Kirkland, QC2011.

127. Van Heeswijk RP, Boogaerts G, De Paepe E, et al. The effect of different types of food on the bioavailability of the investigational HCV protease inhibitor telaprevir (abstract PK_19). Presented at: 6th International Workshop on Clinical Pharmacology of Hepatitis Therapy. Cambridge, June 22 to 23, 2011.

128. Sulkowski M, Pol S, Cooper C, et al. Boceprevir + pegylated interferon + ribavirin for the treatment of HCV/HIV-co-infected patients: End of treatment (week-48) interim results (abstract 47). Program and abstracts of the 19th Conference on Retroviruses and Opportunistic Infections. Seattle, March 5 to 8, 2012.

129. Dieterich D, Soriano V, Sherman K, et al. Telaprevir in combination with pegylated interferon- $\alpha-2 \mathrm{a}+\mathrm{RBV}$ in $\mathrm{HCV} / \mathrm{HIV}-\mathrm{co}-$ infected patients: A 24-week treatment interim analysis (abstract 46). Program and abstracts of the 19th Conference on Retroviruses and Opportunistic Infections. Seattle, March 5 to 8, 2012.

130. Slim J, Mallolas J, Pol S, al. E. Response to antiretroviral therapy is maintained during concomitant use of boceprevir + peginterferon/ ribavirin in a phase IIb study of HIV/HCV co-infected patients (abstract WEPE 053). Program and abstracts of the XIX World AIDS Conference. Washington, DC: July 22 to 27, 2012.

131. Sulkowski M, Sherman K, Soriano V, et al. Telaprevir in combination with peginterferon alfa-2a/ribavirin in HCV/HIV co-infected patients: SVR24 final study results (abstract 1408454). Program and abstracts of the 63rd Annual Meeting of the American Association for the Study of Liver Diseases. Boston, November 9 to 13, 2012.

132. Bronowicki JP, Davis M, Flamm S, et al. Sustained virologic response (SVR) in prior pegintereron/ribavirin (PR) treatment failures after retreatment with boceprevir (BOC)-+-PR: The PROVIDE Study interim results. 47th Annual Meeting of the European Association for the Study of the Liver. Barcelona, April 18 to 22, 2012. J Hepatol 2012;56(Suppl 2):S6.

133. Cotte L, Braun J, Lascoux-Combe C, et al. High early virologic response with telaprevir-pegylated interferon-ribavirin in treatmentexperienced HCV genotype 1/HIV co-infected patients (abstract 36). 
ANRS HC26 TelapreVIH Study. Program and abstract of the 20th Conference on Retroviruses and Opportunistic Infections. Atlanta, March 3 to 6, 2013.

134. Poizette-Martin I, Bellissant E, Piroth L, et al. ANRS-HC27 BocepreVIH interim analysis: High early virologic response with boceprevir + pegylated interferon + ribivirin in hepatitis $\mathrm{C}$ virus/ HIV co-infected patients with previous failure to pegylated interferon + ribivirin (abstract 37). Program and abstract of the 20th Conference on Retroviruses and Opportunistic Infections. Atlanta, March 3 to 6, 2013.

135. Vachon ML, Factor SH, Branch AD, et al. Insulin resistance predicts re-treatment failure in an efficacy study of peginterferonalpha-2a and ribavirin in HIV/HCV co-infected patients. J Hepatol 2011;54:41-7.

136. Dieterich D, Rockstroh J, Orkin C, et al. Simeprevir with pegylated interferon/ribavirin in patients co-infected with chronic hepatitis $\mathrm{C}$ virus and HIV-1: Week-24 interim analysis of the TMC435-C212 Study (abstract 154LB). Program and abstract of the 20th Conference on Retroviruses and Opportunistic Infections. Atlanta, March 3 to 6, 2013.

137. Carrat F, Bani-Sadr F, Pol S, et al. Pegylated interferon alfa-2b vs standard interferon alfa-2b, plus ribavirin, for chronic hepatitis $\mathrm{C}$ in HIV-infected patients: A randomized controlled trial. JAMA 2004;292:2839-48.

138. Torriani FJ, Rodriguez-Torres M, Rockstroh JK, et al. Peginterferon alfa-2a plus ribavirin for chronic hepatitis $\mathrm{C}$ virus infection in HIVinfected patients. N Engl J Med 2004;351:438-50.

139. Nunez M, Miralles C, Berdun MA, et al. Role of weight-based ribavirin dosing and extended duration of therapy in chronic hepatitis C in HIV-infected patients: The PRESCO trial. AIDS Res Hum Retroviruses 2007;23:972-82.

140. Hadziyannis SJ, Sette H Jr, Morgan TR, et al. Peginterferon-alpha2a and ribavirin combination therapy in chronic hepatitis $\mathrm{C}$ : A randomized study of treatment duration and ribavirin dose. Ann Intern Med 2004;140:346-55.

141. Jacobson IM, Brown RS Jr, Freilich B, et al. Peginterferon alfa-2b and weight-based or flat-dose ribavirin in chronic hepatitis $\mathrm{C}$ patients: A randomized trial. Hepatology 2007;46:971-81.

142. Shiffman ML, Suter F, Bacon BR, et al. Peginterferon alfa-2a and ribavirin for 16 or 24 weeks in HCV genotype 2 or 3 . N Engl J Med 2007;357:124-34.

143. Pérez-Olmeda M, Nunez M, Romero M, et al. Pegylated IFNalpha2b plus ribavirin as therapy for chronic hepatitis $\mathrm{C}$ in HIVinfected patients. AIDS 2003;17:1023-8.

144. Voigt E, Schulz C, Klausen G, et al. Pegylated interferon alpha-2b plus ribavirin for the treatment of chronic hepatitis $\mathrm{C}$ in HIVcoinfected patients. J Infect 2006;53:36-42.

145. Zanini B. Abstract 27. Program and abstracts of the Second International Workshop on HIV \& Hepatitis Co-infection. Amsterdam, January 12 to $14,2006$.

146. Hopkins S, Lambourne J, Farrell G, et al. Role of individualization of hepatitis $\mathrm{C}$ virus (HCV) therapy duration in $\mathrm{HIV} / \mathrm{HCV}$ coinfected individuals. HIV Med 2006;7:248-54.

147. Mangia A, Santoro R, Minerva N, et al. Peginterferon alfa-2b and ribavirin for 12 vs. 24 weeks in HCV genotype 2 or 3. N Engl J Med 2005;352:2609-17.

148. Zeuzem S, Hultcrantz R, Bourliere M, et al. Peginterferon alfa-2b plus ribavirin for treatment of chronic hepatitis $\mathrm{C}$ in previously untreated patients infected with HCV genotypes 2 or 3. J Hepatol 2004;40:993-9.

149. Soriano V, Puoti M, Sulkowski M, et al. Care of patients coinfected with HIV and hepatitis C virus: 2007 updated recommendations from the HCV-HIV International Panel. AIDS 2007;21:1073-89.

150. Jaeckel E, Cornberg M, Wedemeyer $\mathrm{H}$, et al. Treatment of acute hepatitis C with interferon alfa-2b. N Engl J Med 2001;345:1452-7.

151. Boesecke C, Rockstroh JK. Treatment of acute hepatitis C infection in HIV-infected patients. Curr Opin HIV AIDS 2011;6:278-84.

152. Nomura H, Sou S, Tanimoto H, et al. Short-term interferon-alfa therapy for acute hepatitis C: A randomized controlled trial. Hepatology 2004;39:1213-9.

153. Matthews GV, Hellard M, Haber P, et al. Characteristics and treatment outcomes among HIV-infected individuals in the Australian Trial in Acute Hepatitis C. Clin Infect Dis 2009;48:650-8.

154. Rockstroh JK, Bhagani S, Benhamou Y, et al. European AIDS Clinical Society (EACS) guidelines for the clinical management and treatment of chronic hepatitis B and C coinfection in HIVinfected adults. HIV Med 2008;9:82-8.

155. Kaplan JE, Benson C, Holmes KH, et al. Guidelines for prevention and treatment of opportunistic infections in HIV-infected adults and adolescents: Recommendations from CDC, the National Institutes of Health, and the HIV Medicine Association of the Infectious Diseases Society of America. MMWR Recomm Rep 2009;58(RR-4):1-207.

156. Morello J, Soriano V, Barreiro P, et al. Plasma ribavirin trough concentrations at week 4 predict hepatitis $\mathrm{C}$ virus (HCV) relapse in HIV-HCV-coinfected patients treated for chronic hepatitis C. Antimicrob Agents Chemother 2010;54:1647-9.

157. Vispo E, Barreiro P, Pineda JA, et al. Low response to pegylated interferon plus ribavirin in HIV-infected patients with chronic hepatitis C treated with abacavir. Antivir Ther 2008;13:429-37.

158. Laufer N, Laguno M, Perez I, et al. Abacavir does not influence the rate of virological response in HIV-HCV-coinfected patients treated with pegylated interferon and weight-adjusted ribavirin. Antivir Ther 2008;13:953-7.

159. Mira JA, Lopez-Cortes LF, Barreiro P, et al. Efficacy of pegylated interferon plus ribavirin treatment in HIV/hepatitis C virus co-infected patients receiving abacavir plus lamivudine or tenofovir plus either lamivudine or emtricitabine as nucleoside analogue backbone. J Antimicrob Chemother 2008;62:1365-73.

160. Amorosa VK, Slim J, Mounzer K, et al. The influence of abacavir and other antiretroviral agents on virological response to HCV therapy among antiretroviral-treated HIV-infected patients. Antiviral Ther 2010;15:91-9.

161. Berenguer J, von Wichmann MA, Quereda C, et al. Effect of accompanying antiretroviral drugs on virological response to pegylated interferon and ribavirin in patients co-infected with HIV and hepatitis C virus. J Antimicrob Chemother 2011;66:2843-9.

162. Van den Eynde E, Quer J, Cubero M, et al. Abacavir co-administration does not interfere with the suppressive activity of ribavirin in an HCV replicon system (abstract 963). Presented at the 18th Conference on Retroviruses and Opportunistic Infections. Boston, February 27 to March 2, 2011.

163. Andrade A, Hendrix C, Fuchs E, et al. Steady-state plasma and intracellular ribavirin concentrations are not significantly altered by abacavir co-administration in hepatitis $\mathrm{C}$ virus infected patients (abstract 538). The 20th Conference of Retroviruses and Opportunistic Infections. Atlanta, March 3 to 6, 2013.

164. Panel on Antiretroviral Guidelines for Adults and Adolescents. Guidelines for the use of antiretroviral agents in HIV-infected adults and adolescents. Department of Health and Human Services. Federal register 2012:1-239.

165. Tseng A, Foisy M. Important drug-drug interactions in HIV-infected persons on antiretroviral therapy: An update on new interactions between HIV and non-HIV Drugs. Curr Infect Dis Rep 2012;14:67-82.

166. Kiser J, Burton J, Anderson P, Everson G. Review and management of drug interactions with boceprevir and telaprevir. Hepatology 2012;55:1620-8.

167. Vance DE, Mugavero M, Willig J, Raper JL, Saag MS. Aging with HIV: A cross-sectional study of comorbidity prevalence and clinical characteristics across decades of life. J Assoc Nurses AIDS Care 2011;22:17-25.

168. Marzolini C, Elzi L, Gibbons S, et al. Prevalence of comedications and effect of potential drug-drug interactions in the Swiss HIV Cohort Study. Antivir Ther 2010;15:413-23.

169. Vertex Pharmaceuticals Inc. Incivek (telaprevir) Product Monograph. Cambridge, MA2011.

170. Hulskotte EG, Feng H-P, Xuan F, et al. Pharmacokinetic interaction between the HCV protease inhibitor boceprevir and ritonavir-boosted HIV-1 protease inhibitors atazanavir, lopinavir, and darunavir (abstract 771LB). The 19th Conference on Retroviruses and Opportunistic Infections. Seattle, March 5 to 8, 2012.

171. Schwarze-Zander C, Rockstroh JK. HIV protease inhibitors in combination with boceprevir: Are drug-drug interactions the same for all patients? AIDS 2012;26:1845-6.

172. Van Heeswijk RP, Vandevoorde A, Boogaerts G, et al. Pharmacokinetic interactions between ARV agents and the investigational HCV protease inhibitor TVR in healthy volunteers (abstract 119). The 18th Conference on Retroviruses and Opportunistic Infections. Boston, February 27 to March 2, 2011. 
173. Kakuda TN, Leopold L, Nijs S, et al. Pharmacokinetic interaction between etravirine or rilpivirine and telaprevir: A randomised, twoway crossover trial (abstract $\mathrm{O}_{-} 18$ ). The 13th International Workshop on Clinical Pharmacology of HIV Therapy. Barcelona, April 16 to 18,2012

174. Schering Corporation, a subsidiary of Merck \& Co. Victrelis (boceprevir) Product Monograph. Whitehouse Station, New Jersey, 2011.

175. Hammond K, Wolfe P, Burton J, et al. Pharmacokinetic interaction between boceprevir and etravirine in HIV/HCV seronegative volunteers (abstract O_15).The 13th International Workshop on Clinical Pharmacology of HIV Therapy. Barcelona, April 16 to 18, 2012.

176. Rhee E, Feng H, Xuan F, et al. Absence of a significant pharmacokinetic interaction between the hepatitis $\mathrm{C}$ protease inhibitor boceprevir and the HIV-1 NNRTI rilpivirine (abstract 537). The 20th Conference on Retroviruses and Opportunistic Infections. Atlanta, March 3 to 6, 2013.

177. de Kanter C, Blonk M, Colbers A, Fillekes Q, Schouwenberg B, Burger D. The influence of the HCV protease inhibitor boceprevir on the pharmacokinetics of the HIV integrase Inhibitor raltegravir (abstract 772LB). Paper presented at: 19th Conference on Retroviruses and Opportunistic Infections. Seattle, March 5 to 8, 2012.

178. Van Heeswijk RPG, Garg V, Boogaerts G, et al. The pharmacokinetic interaction between telaprevir and raltegravir in healthy volunteers (abstract A1-1738a). The 51st Interscience Conference on Antimicrobial Agents and Chemotherapy. Chicago, September 17 to 20, 2011.

179. Moreno A, Quereda C, Montes M, et al. Safe coadministration of raltegravir-based HAART in HIV-infected patients with HCVcirrhosis receiving triple therapy with telaprevir or boceprevir. J Acquir Immune Defic Syndr 2012;61:e47-49.

180. Eron JJ, Young B, Cooper DA, et al. Switch to a raltegravir-based regimen versus continuation of a lopinavir-ritonavir-based regimen in stable HIV-infected patients with suppressed viraemia (SWITCHMRK 1 and 2): Two multicentre, double-blind, randomised controlled trials. Lancet 2010;375:396-407.

181. Gilead Sciences Canada Inc. Stribild (elvitegravir, cobicistat, emtricitabine, tenofovir disoproxil fumarate) Product Monograph. Mississauga, November 26, 2012.

182. Johnson M, Borland J, Chen S, Savina P, Wynne B, Piscitelli S. The effect of boceprevir and telaprevir on dolutegravir pharmacokinetics, in healthy adult subjects (abstract O_16). The 14th International Workshop on Clinical Pharmacology of HIV Therapy. Amsterdam, April 22 to 24, 2013.

183. Kasserra C, Hughes E, Treitel M, Gupta S, O’Mara E. Clinical pharmacology of boceprevir: Metabolism, excretion, and drug-drug interactions (abstract 118). The 18th Conference on Retroviruses and Opportunistic Infections. Boston, February 27 to March 2, 2011.

184. Van Heeswijk R, Gysen V, Googaerts G, et al. The pharmacokinetic interaction between tenofovir disoproxil fumarate and the investigational HCV protease inhibitor telaprevir (abstract A-966). The 48th Interscience Conference on Antimicrobial Agents and Chemotherapy. Washington, October 25 to 28, 2008.

185. Vourvahis M, Plotka A, Kantaridis C, Fang A, Heera J. The effect of boceprevir and telaprevir on the pharmacokinetics of maraviroc: An open-label, fixed-sequence study in healthy volunteers (abstract O 17). The 14th International Workshop on Clinical Pharmacology of HIV Therapy. Amsterdam, April 22 to 24, 2013.

186. Tseng A, Foisy M. Important drug-drug interactions in HIV-infected persons on antiretroviral therapy: An update on new interactions between HIV and non-HIV drugs. Curr Infect Dis Rep 2012;14:67-82

187. Van Heeswijk RPG, Vandevoorde A, Verboven P, et al. The pharmacokinetic interaction between methadone and the investigational HCV protease inhibitor telaprevir (abstract PK_18). The 6th International Workshop on Clinical Pharmacology of Hepatitis Therapy. Cambridge, June 22 to 23, 2011.

188. Luo X, Trevejo J, Van Heeswijk RP. No significant effect of the HCV protease inhibitor telaprevir on pharmacokinetics and pharmacodynamics of buprenorphine in $\mathrm{HCV}$-negative volunteers (Abst). Presented at: HEP DART. Koloa, December 4 to 8, 2011.

189. Hulskotte EG, Feng H-P, Bruce RD, et al. Pharmacokinetic interaction between $\mathrm{HCV}$ protease inhibitor boceprevir and methadone or buprenorphine in subjects on stable maintenance therapy (abstract PK_09). The 7th International Workshop on Clinical Pharmacology of Hepatitis Therapy. Cambridge, June 27 to $28,2012$.

190. Cooper CL. Managing the side events of therapy. In: Shiffman ML, ed. Chronic Hepatitis C Virus: Advances in Treatment. Promise for the Future. New York: Springer, 2012;171-82.

191. Sulkowski MS, Poordad F, Manns MP, et al. Anemia during treatment with peginterferon alfa-2b/ribavirin and boceprevir: Analysis from the serine protease inhibitor therapy 2 (SPRINT-2) trial. Hepatology 2013;57:974-84.

192. Cooper CL, Al-Bedwawi S, Lee C, Garber G. Rate of infectious complications during interferon-based therapy for hepatitis $\mathrm{C}$ is not related to neutropenia. Clin Infect Dis 2006;42:1674-8.

193. Antonini MG, Babudieri S, Maida I, et al. Incidence of neutropenia and infections during combination treatment of chronic hepatitis $\mathrm{C}$ with pegylated interferon alfa-2a or alfa-2b plus ribavirin. Infection 2008;36:250-5.

194. Roomer R, Hansen BE, Janssen HL, de Knegt RJ. Risk factors for infection during treatment with peginterferon alfa and ribavirin for chronic hepatitis C. Hepatology 2010;52:1225-31.

195. Talal AH, Liu RC, Zeremski M, et al. Randomized trial comparing dose reduction and growth factor supplementation for management of hematological side effects in HIV/hepatitis $\mathrm{C}$ virus patients receiving pegylated-interferon and ribavirin. J Acquir Immune Defic Syndr 2011;58:261-8.

196. Fontaine H, Hezode C, Dorival C, et al. SVR12 rates and safety of triple therapy including telaprevir or boceprevir in 221 cirrhotic non responders treated in the French Early Access Program (ANRS CO20-CUPIC) (abstract 60). The 48th Annual Meeting of the European Association for the Study of the Liver (EASL 2013). Amsterdam, April 24 to 28, 2013.

197. Miro JM, Torre-Cisnero J, Moreno A, et al. [GESIDA/GESITRASEIMC, PNS and ONT consensus document on solid organ transplant (SOT) in HIV-infected patients in Spain (March, 2005)]. Enferm Infecc Microbiol Clin 2005;23:353-62.

198. O'Grady J, Taylor C, Brook G. Guidelines for liver transplantation in patients with HIV infection (2005). HIV Med 2005;(6 Suppl 2):149-53.

199. Stock PG, Roland ME. Evolving clinical strategies for transplantation in the HIV-positive recipient. Transplantation 2007;84:563-71.

200. Miro JM, Aguero F, Laguno M, et al. Liver transplantation in HIV/hepatitis co-infection. J HIV Ther 2007;12:24-35.

201. Sugawara Y, Tamura S, Kokudo N. Liver transplantation in HCV/ HIV positive patients. World J Gastrointest Surg 2011;3:21-8.

202. Cooper C, Kanters S, Klein M, et al. Liver transplant outcomes in HIV-infected patients: A systematic review and meta-analysis with synthetic cohort. AIDS 2011;25:777-86.

203. Miro JM, Montejo M, Castells L, et al. Outcome of HCV/HIVcoinfected liver transplant recipients: A prospective and multicenter cohort study. Am J Transplant 2012;12:1866-76.

204. Anadol E, Beckebaum S, Radecke K, et al. Orthotopic liver transplantation in human-immunodeficiency-virus-positive patients in Germany. AIDS Res Treat 2012;2012:197501.

205. Seden K, Back D. Directly acting antivirals for hepatitis C and antiretrovirals: Potential for drug-drug interactions. Curr Opin HIV AIDS 2011;6:514-26.

206. Wilby KJ, Greanya ED, Ford JA, Yoshida EM, Partovi N. A review of drug interactions with boceprevir and telaprevir: Implications for HIV and transplant patients. Ann Hepatol 2012;11:179-85.

207. Hulskotte EG, Gupta S, Xuan F, et al. Pharmacokinetic interaction between the HCV protease inhibitor boceprevir and the calcineurin inhibitors cyclosporine and tacrolimus (abst). Presented at HEP DART. Koloa, December 4 to 8, 2011.

208. Garg V, Van Heeswijk RP, Lee JE, Alves K, Nadkarni P, Luo X. Effect of telaprevir on the pharmacokinetics of cyclosporine and tacrolimus. Hepatology 2011;54:20-7.

209. Saxena V, Terrault N. Hepatitis C virus treatment and liver transplantation in the era of new antiviral therapies. Curr Opin Organ Transplant 2012;17:216-24.

210. Charlton M. Telaprevir, boceprevir, cytochrome P450 and immunosuppressive agents - A potentially lethal cocktail. Hepatology 2011;54:3-5.

211. Shiffman RN, Shekelle P, Overhage JM, Slutsky J, Grimshaw J, Deshpande AM. Standardized reporting of clinical practice 
guidelines: A proposal from the Conference on Guideline Standardization. Ann Intern Med 2003;139:493-8.

212. Ghany MG, Nelson DR, Strader DB, Thomas DL, Seeff LB. An update on treatment of genotype 1 chronic hepatitis $\mathrm{C}$ virus infection: 2011 practice guideline by the American Association for the Study of Liver Diseases. Hepatology 2011;54:1433-44.

213. Vierling J, Flamm S, Gordon S, et al. Efficacy of boceprevir in prior null responders to peginterferon/ribavirin: The PROVIDE Study (abstract 931). Programs and abstracts of the 62nd Annual Meeting of the American Association for the Study of Liver Diseases. San Francisco, November 4 to 8, 2011.

214. Garg V, Chandorkar G, Yang Y, et al. The effect of CYP3A inhibitors and inducers on the pharmacokinetics of telaprevir (abstract PK_13). Presented at the 6th International Workshop on Clinical Pharmacology of Hepatitis Therapy. Cambridge, June 22 to 23, 2011. 


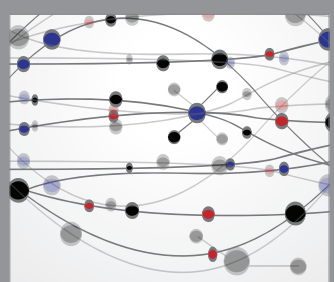

The Scientific World Journal
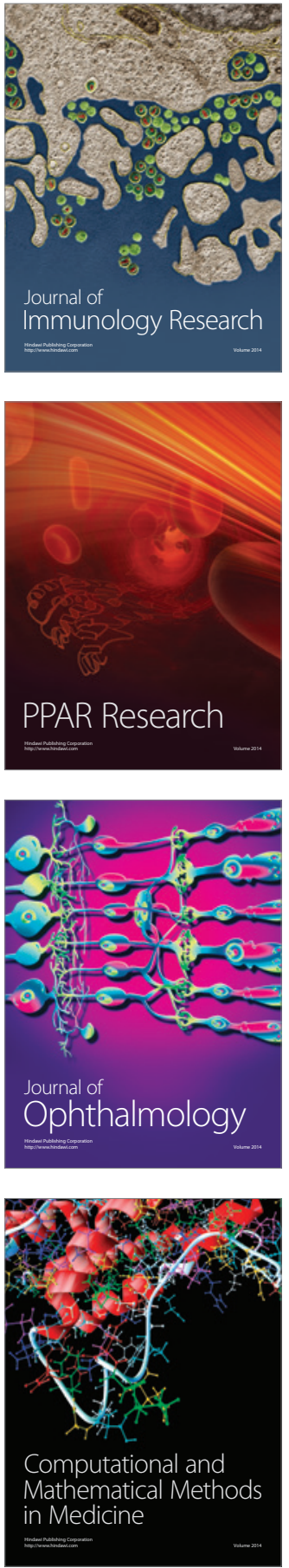

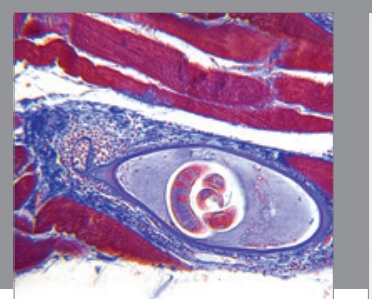

Gastroenterology Research and Practice

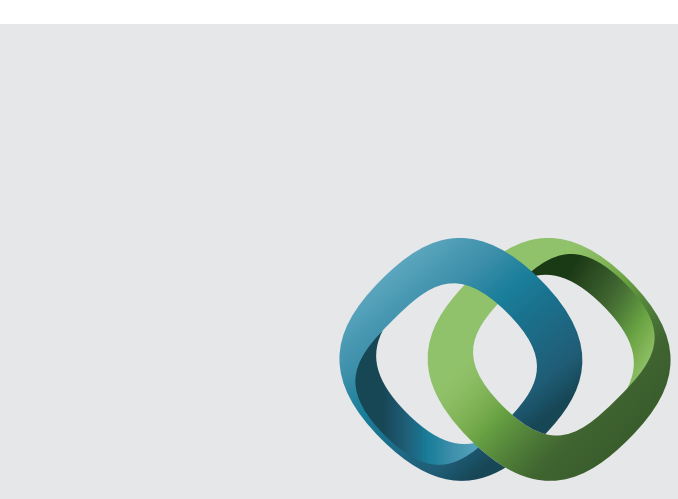

\section{Hindawi}

Submit your manuscripts at

http://www.hindawi.com
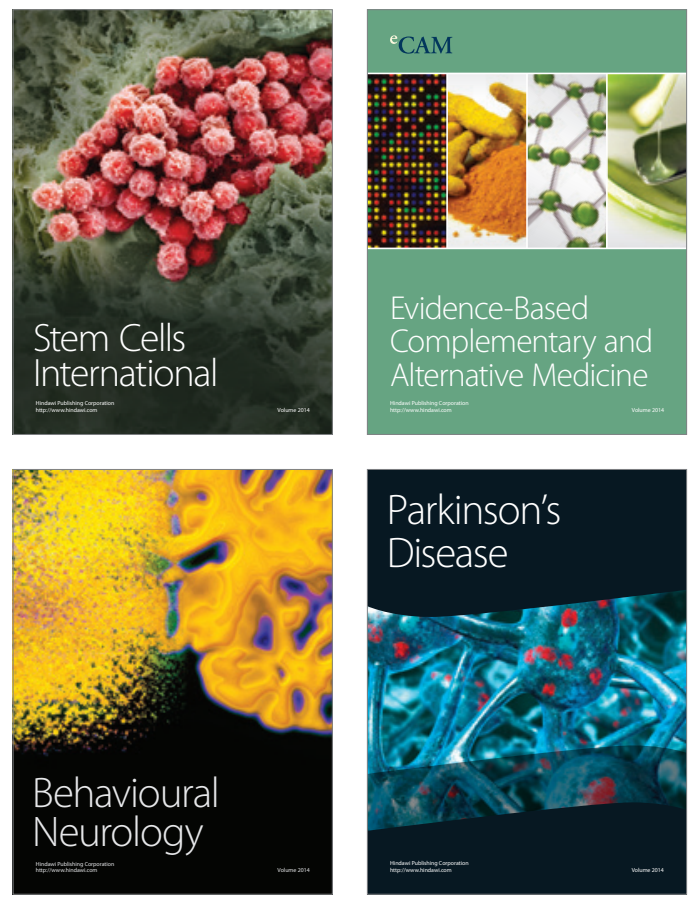
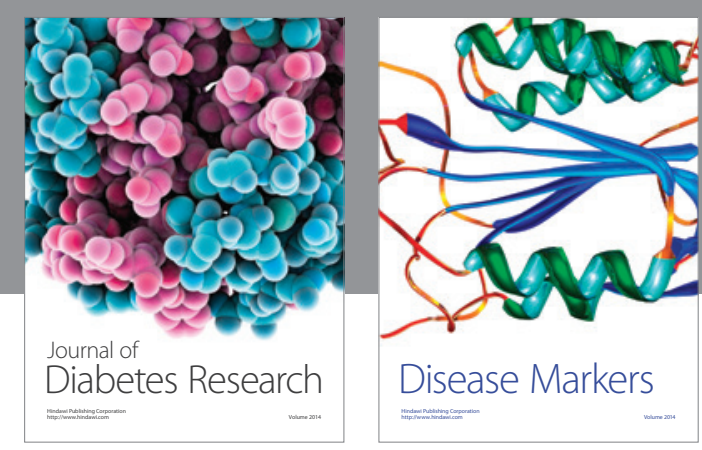

Disease Markers
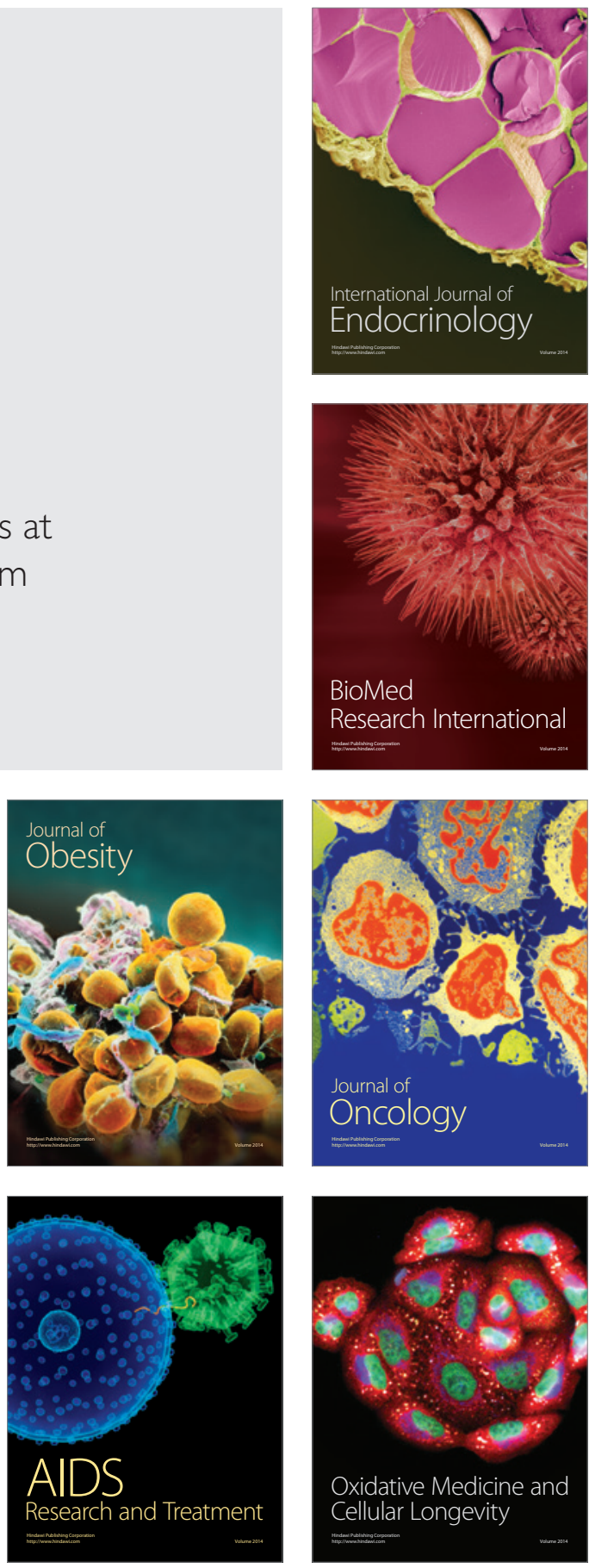